\title{
CHROMOSOME PAIRING ANALYSIS IN HAPLOID WHEAT BY SPREADING OF MEIOTIC NUCLEI
}

\author{
by \\ XINGZHI WANG \\ Department of Physiology, Carlsberg Laboratory, \\ Gamle Carlsberg Vej 10, DK-2500 Copenhagen Valby \\ and \\ Institute of Genetics, Academia Sinica, Beijing, China
}

Keywords: Synaptonemal complex, homoeologues, chromosome 5B

\begin{abstract}
Synapsis and chiasma formation have been analyzed at the ultrastructural level in trihaploid wheat with and without chromosome 5B by spreading of microsporocytes. The euhaploids were obtained by anther culture of euhexaploid or monosomic 5B Chinese Spring wheat or from the hexaploid Chinese winter wheat variety Kedong. All three types of euhaploid wheat were virtually achiasmatic. Analysis of 31 spread zygotene nuclei, covering the entire zygotene stage, revealed that synaptonemal complex formation primarily was initiated interstitially whereafter the formation proceeded in the telomeric regions. Pairing partner exchanges were frequent, most of the lateral components within the individual nucleus being combined into a single multiple association. As synapsis proceeded the number of pairing partner exchanges decreased and at late zygotene many associations involved only two or three lateral components. The mean degree of synapsis achieved in haploids of Chinese Spring amounted to $35-40 \%$ while in haploids from Kedong up to $90 \%$ of the complement was combined with synaptonemal complexes. Analysis of a nullisomic 5B haploid plant derived from Chinese Spring wheat revealed a 45-fold increase in the number of chiasmata per cell at metaphase I compared to euhaploids. The differences in number of chiasmata were correlated with a nearly twofold increase in the number of pairing partner exchanges per lateral component compared to that found in euhaploid wheat.

The elimination of the synaptonemal complex during diplotene was monitored in 37 euhaploid nuclei ranging in stage from early diplotene to diakinesis. As in hexaploid wheat the degradation of the synaptonemal complexes started at a low number of sites, generating a number of segments. These were thereafter degraded from their ends until by diakinesis elimination was complete or almost so.
\end{abstract}

\section{INTRODUCTION}

In trihaploids of wheat only a low number of chiasmata form between the homoeologues of the $\mathrm{A}, \mathrm{B}$ and $\mathrm{D}$ genomes. In 12 analyzed haploids there were thus a mean of 1.05 bivalents and 0.02 trivalents per cell at metaphase I (21). These few chiasmata form primarily between homoeologous chromosomes (19). In trihaploid wheat unreduced egg cells occasionally form which, upon fertilization with pollen from allohexaploid wheat, gives rise to viable hexaploid progeny. As crossing over between homoeologous and nonhomologous chromosomes in the trihaploid results in translocations, the presence of translocation heterozygosity in such progeny may signify previous synapsis and crossing over in the haploid. In nine of the thirteen translocations identified, homoeologues belonging to the $\mathrm{A}$ and $\mathrm{D}$ genomes were involved, while the remaining four translocations had occurred between nonhomologous chromosomes (19). 
In the absence of chromosome 5B, chiasma formation is drastically increased. Analysis of 5 haploids, nullisomic for chromosome $5 \mathrm{~B}$ thus revealed a mean of 3.72 bivalents, 1.64 trivalents and 0.07 quadrivalents per cell at metaphase I (21). Although the chromosomes combined by chiasmata have not been identified it is considered likely that the chiasmata have formed primarily between the homoeologues as is the case for allohexaploid wheat (22) and hybrids between hexaploid wheat and related species (see 15, 28 for review).

It is at present evident that the lack of crossing over in haploids cannot be attributed to asynapsis. Already in 1933 MCCLINTOCK (17) pointed out that chromosome synapsis in monohaploids of Zea mays was as intimate as synapsis in the diploid. Similar observations from monohaploids of Antirrhinum majus led RIEGER (20) to propose that chromosomes had a general tendency for synapsis during meiosis which in the diploid is not apparent due to the presence of a homologous partner. These concepts have been supported by ultrastructural studies, documenting the presence of synaptonemal complexes in haploids of e.g. maize (27) and Petunia and Antirrhinum (24). In monohaploids of barley up to $60 \%$ of the complement was combined with a synaptonemal complex (5). In hybrids of Gossypium a high degree of synapsis was reported from light microscopic studies (2) and synaptonemal complexes identified in hybrids of Lycopersicon and Solanum (18). It is now evident from a large number of ultrastructural studies that while synapsis in diploids and polyploids is a highly specific process of homologue pairing at early zygotene, the requirement for homology is abolished at the end of zygotene and at pachytene where synaptonemal complexes may form between any chromosome segment, irrespective of homology $(15,32)$. This later phase of unspecific synapsis may account for the synaptonemal complex formation in the monohaploids and the hybrids.

As there in allopolyploids is partial homology between the parental genomes it is to be expected that synapsis in the polyhaploids derived from them occur even more readily than in monohaploids. In hybrids of tetraploid/ hexaploid wheat with diploid rye substantial synaptonemal complex formation has been reported (1). These studies also documented the presence of recombination nodules of normal morphology in the hybrids between hexaploid wheat and rye.

The present paper is addressed to an analysis of synapsis and chiasma formation in trihaploids of allohexaploid wheat, $T$. aestivum in order to assess the effect of chromosome $5 \mathrm{~B}$ on synaptonemal complex formation and crossing over/chiasma formation between the three homoeologous genomes of the common wheat. This study is part of a larger investigation aiming at characterizing the effect of chromosome 5B on meiosis in wheat, which includes ultrastructural analyses of allohexaploid wheat nullisomic for chromosome $5 \mathrm{~B}(10)$, monosomic for $5 \mathrm{~B}(9)$, euploid wheat $(7,8,16)$, allohexaploid wheat monoisosomic, diisosomic and triisosomic for the long arm of chromosome $5 \mathrm{~B}(11,33)$ as well as wheat-rye hybrids nullisomic for $5 \mathrm{~B}$, euploid hybrids and hybrids carrying an isochromosome for the long arm of 5B (28). A summary and discussion of the results are given in (15).

\section{MATERIALS AND METHODS}

\subsection{Materials}

Euploid and monosomic 5B T. aestivum cv. Chinese Spring and euploid T. aestivum cv. Kedong were used as donor plants for the anther culture. Seeds of monosomic 5B plants were kindly provided by Dr. T. MILLER, Plant Breeding Institute, Cambridge. The donor plants were grown in a heated glass house at $20^{\circ} \mathrm{C}$ during the day and $15^{\circ} \mathrm{C}$ at night.

\subsection{Methods}

\subsubsection{Anther culture}

Spikes containing microspores at the mid to late uninucleate stage were excised from the donor plants and sterilized by immersion in a $0.1 \%$ aqueous solution of mercuric chloride for eight minutes. After three rinses in redistilled sterilized water, the anthers were taken out and placed on Potato II media as described by Chuang et al. (3). The calli and embryoids forming from the microsporocytes of the anthers were subsequently transferred to 190-2 

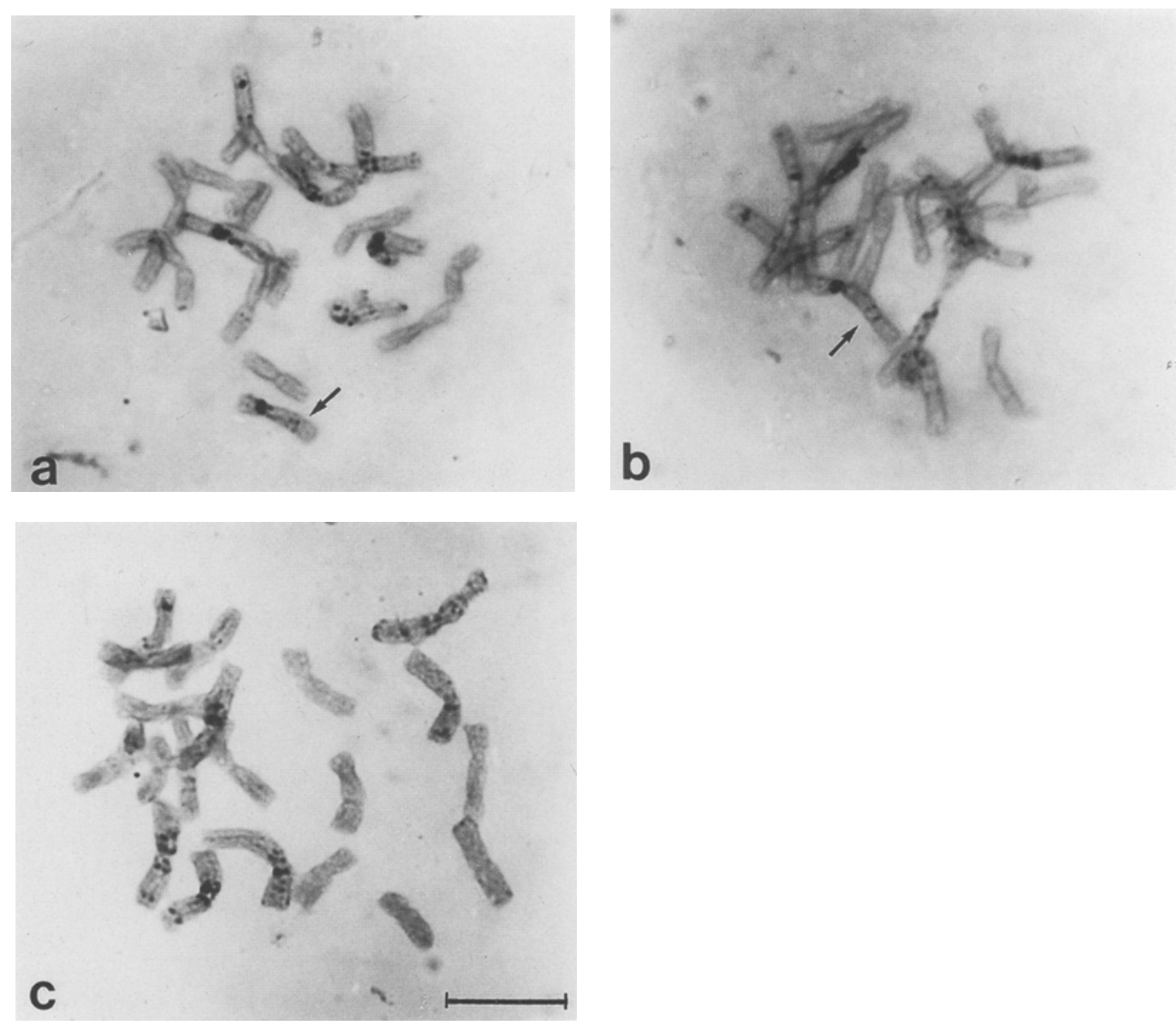

Figure 1. Phase contrast photographs of N-banded metaphase complements of root tips from euhaploid wheat (Figures $\mathrm{la}$ and $\mathrm{Ib}$ ) and a haploid nullisomic for chromosome 5B (Figure 1c). The N-banded chromosome 5B in Figures $\mathrm{la}$ and $\mathrm{lb}$ are denoted by arrows. (Bar $=10 \mu \mathrm{m})$

differentiation medium (4). Green plants derived from the calli and embryoids were grown in a glass house under the same conditions as the donor plants.

\subsubsection{Light and electron microscopy}

The chromosome number of the pollen plants as well as of the monosomic $5 \mathrm{~B}$ donor plants was determined from the squashes of root tips as described by WANG and Hu (29) using a cellulase and pectinase mixture to digest the cell walls of the root tips. The procedures for $\mathrm{N}$-banding, fixation and squashing of microsporocytes as well as the procedures for electron microscopy have been described elsewhere $(8,9)$.

\section{RESULTS}

\subsection{Pollen plants}

A total of 57,487 anthers of euploid and monosomic $5 \mathrm{~B}$ Chinese Spring wheat were placed on Potato II media. From these anthers 3,325 calli and embryoids were formed from which 115 green plants were generated. The majority of the green pollen plants were either euallohexaploids ( 50 plants) or euhaploids (41 
Table I. Chromosome configuration and number of chiasmata per cell at metaphase I in euhaploid wheat (1 $\times 5 B)$ obtained by anther culture of allohexaploid Chinese Spring wheat (CS), monosomic 5B Chinese Spring wheat (MCS), the allohexaploid wheat cultivar Kedong (KT) and haploids nullisomic for chromosome 5B (0x5B) derived from monosomic 5B Chinese Spring wheat.

\begin{tabular}{|c|c|c|c|c|c|c|c|}
\hline \multirow[t]{3}{*}{ Genotype } & \multirow{3}{*}{$\begin{array}{l}\text { No. of } \\
\text { cells }\end{array}$} & \multirow{3}{*}{ I } & \multicolumn{4}{|c|}{ Chromosome configuration } & \multirow{2}{*}{$\begin{array}{l}\text { No. of } \\
\text { chiasmata }\end{array}$} \\
\hline & & & & & III & IV & \\
\hline & & & Rod & Ring & & & \\
\hline $\begin{array}{l}1 \times 5 B \\
(C S)\end{array}$ & 120 & 20.72 & 0.14 & -- & --- & --- & 0.14 \\
\hline $\begin{array}{l}1 \times 5 \mathrm{~B} \\
(\mathrm{MCS})\end{array}$ & 120 & 20.67 & 0.16 & --- & --- & -- & 0.16 \\
\hline $\begin{array}{l}1 \times 5 B \\
(\mathrm{KT})\end{array}$ & 120 & 20.56 & 0.21 & -- & 0.01 & --- & 0.23 \\
\hline $\begin{array}{l}0 \times 5 B \\
(\mathrm{MCS})\end{array}$ & 108 & 9.14 & 3.44 & 0.87 & 0.56 & 0.11 & 6.73 \\
\hline
\end{tabular}

plants) having 42 and 21 chromosomes, respectively. Eight of the plants had 40 chromosomes and one plant had 20 chromosomes while the remaining 15 plants were aneuploids. Pollen plant formation from cultivation of anthers from Chinese Spring wheat is thus very inefficient as also noted in other investigations $(25$, 34). Using the same conditions substantially higher frequencies of green pollen plants can be obtained in cultivars such as Kedong.

The genomic constitution of the 21 and 20 chromosome plants was assessed by N-banding technique. The analyses revealed that chromosome 5B was present in the 21 chromosome plants (Figures 1a and $1 \mathrm{~b}$ ) but absent in the 20 chromosome plant (Figure 1c), the latter having the morphological characteristics of nullisomy for $5 \mathrm{~B}$ as seen in hexaploids, namely narrow leaves and less vigorous growth $(10,23)$. In this plant only three tillers formed and there were only few microsporocytes within the anthers.

\subsection{Effect of chromosome $5 B$ on chiasma formation}

The number of chiasmata at metaphase I was counted in the euhaploid plants derived from anthers of euploid Chinese Spring, from anthers of monosomic 5B Chinese Spring and from anthers of the variety Kedong. In all three materials few chiasmata had formed, the mean number of chiasmata per metaphase in the three materials being $0.14,0.16$ and 0.23 (Table I, Figures $2 \mathrm{e}$ and $2 \mathrm{f}$ ). In contrast there was a mean of 6.73 chiasmata per cell in the haploid nullisomic for chromosome 5B (Table I, Figures 2a-2d) (9.14 univalents, 3.44 rod and 0.87 ring bivalents, 0.56 trivalents, 0.11 quadrivalents, 0.01 pentavalents and 0.01 heptavalents). In some cases complex multiple associations had formed which could not be interpreted (Figure $2 \mathrm{~d})$. The chiasma frequencies for the nullisomic 5B haploids are similar to those reported by RILEY (21, see Introduction) while the chiasma frequencies in the euhaploids are somewhat lower (0.14-0.21 bivalents per cell in this study versus 1.05 bivalents and 0.02 trivalents in the material analyzed by RILEY (21)).

\subsection{Synapsis in euhaploid wheat}

The ultrastructural analysis of euhaploids from Chinese Spring wheat comprised a total of 68 nuclei, ranging in stage from early zygotene to late diplotene. The nuclei were from microsporocytes of six pollen plants, all obtained by anther culture of monosomic 5B Chinese Spring wheat. A total of 31 zygotene nuclei were analyzed at the ultrastructural level. Nuclei with less than $10 \%$ of their complements paired with synaptonemal complexes and possessing a welldefined bouquet were assigned to the early zygotene stage while nuclei with no visible bouquet, or with a resolving bouquet and more 

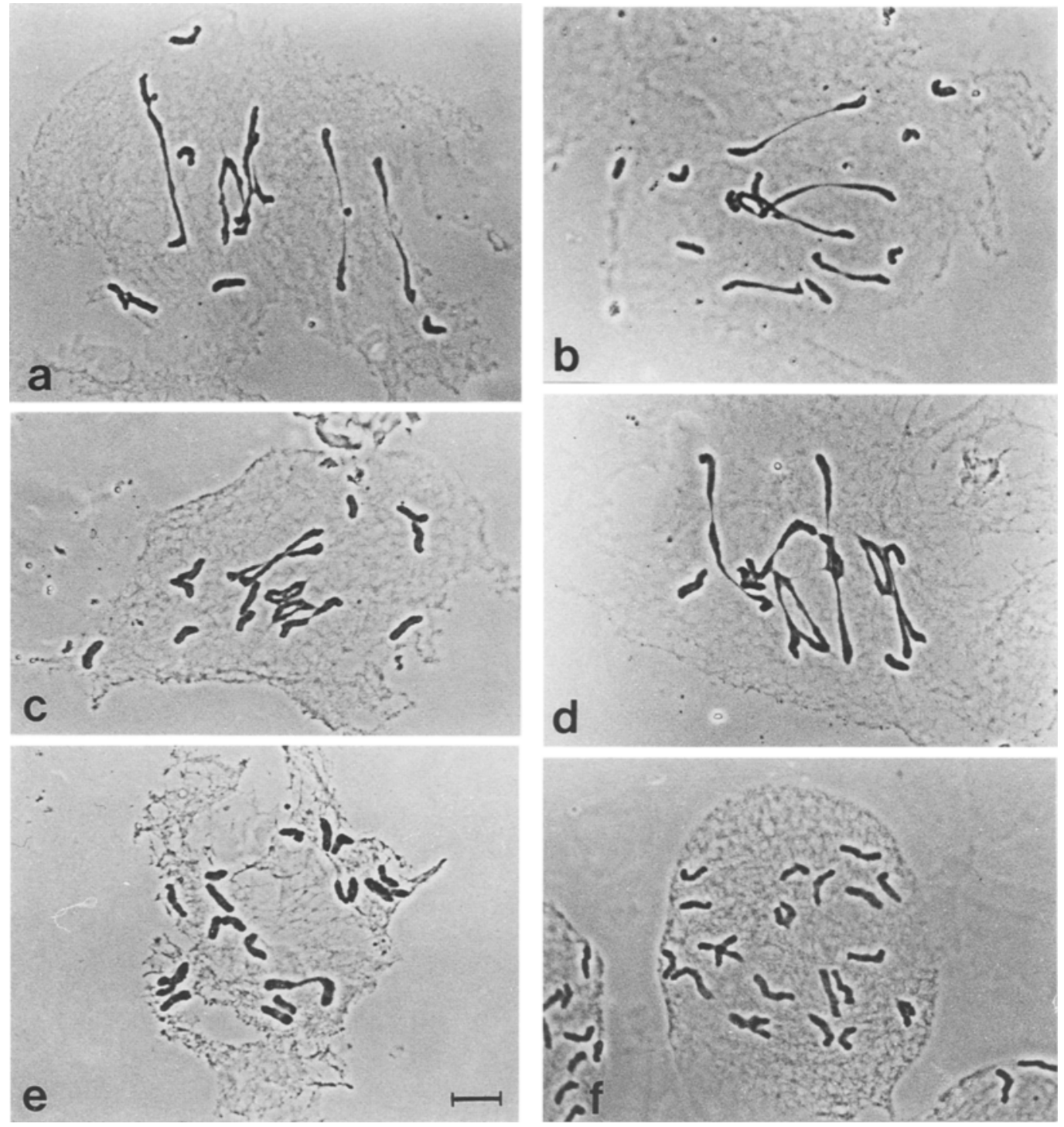

Figure 2. Phase contrast photographs of carbol-fuchsin stained chromosome complements of metaphase-anaphase I in a haplöid nullisomic for chromosome 5B (Figures 2a-d) and euhaploid wheat (Figures 2e-f). In Figure 2a are shown 5 rod bivalents and one trivalent, in Figure $2 \mathrm{~b}$ three rod bivalents and a possible quadrivalent, in Figure $2 \mathrm{cthree}$ rod and two ring bivalents while complex associations are seen in Figure $2 \mathrm{~d}$. Figure $2 \mathrm{e}$ from the euhaploid only reveals one rod bivalent while 21 univalents are present in Figure $2 \mathrm{f}$. $(\operatorname{Bar}=10 \mu \mathrm{m})$

than $10 \%$ synapsis were designated mid-late zygotene nuclei. A distinction between a mid and a late zygotene stage was not attempted.

The analysis of the early zygotene stage comprised tracings of eleven nuclei. The bouquet configuration is distinct as illustrated in the montage of micrographs in Figure 3, where 32 of the 42 telomeres are located in a small area near the nucleolus. In the eleven nuclei the mean degree of synapsis amounted to $5.9 \%$ with a range from $2.2 \%$ to $9.7 \%$, the mean complement length being $2225 \mu \mathrm{m}$ (Table II). Four of the 


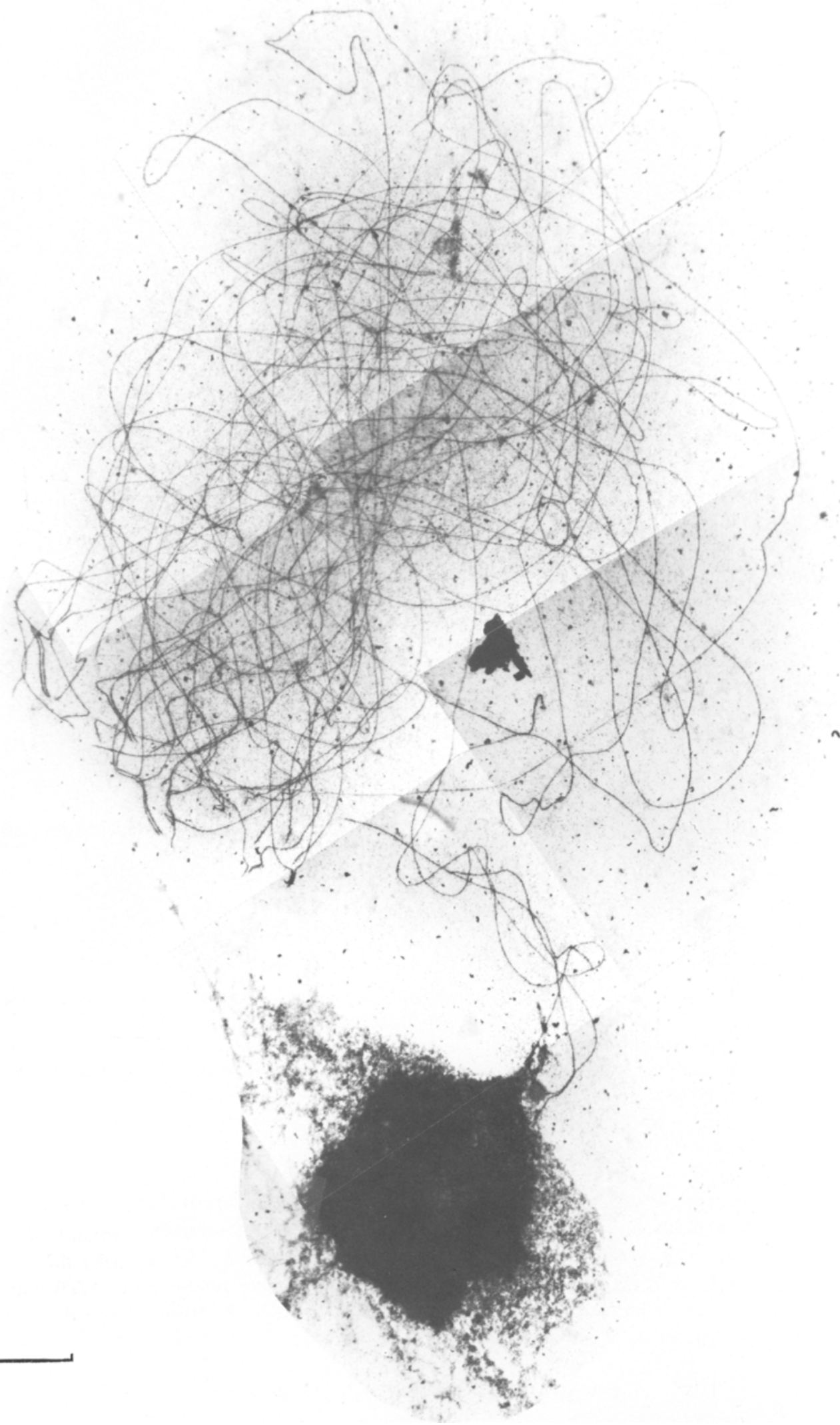


Figure 3. A montage of micrographs of an early zygotene nucleus (EZ3, 3.1\% pairing) from euhaploid wheat. $($ Bar $=5 \mu \mathrm{m})$

eleven nuclei contained less than 30 lateral components or lateral component fragments, while in the remaining seven nuclei more than 30 lateral components or lateral component fragments were present due to intertwining and breakage of the lateral components.

Synaptonemal complex formation is initiated at a large number of sites during this early stage of zygotene, and pairing partner exchanges are frequent (Figures 4, 5 and 8 ). In five of the nuclei where the number of lateral components or lateral component fragments was below 33, most lateral components in the individual nuclei were involved in the same multiple association (Table II). Thus in nucleus EZ11 with 26 lateral components, 23 were in the same multiple association. In nuclei with a pairing percentage of $0-5 \%$ there was a mean number of 18 synaptonemal complex segments with a mean length of $3.6 \mu \mathrm{m}$, while in nuclei with $5-10 \%$ synapsis the mean number of synaptonemal complex segments had increased to 25 with a mean length of $6.9 \mu \mathrm{m}$ (Table IV). At the very beginning of zygotene the synaptonemal complex primarily formed interstitially (Figure 4) as only 2.4 of the 18 segments involved telomeres, while in the $5-10 \%$ pairing range seven out of 25 synaptonemal complex segments had formed between the telomeres.

In this, as well as in the other ultrastructural studies of wheat in this series, an identification of the individual chromosomes or an assignment to any of the three genomes has not been attempted due to the lack of appropriate markers for identification such as centromeres. Likewise, the occasional breakage of the lateral components in the spread nuclei hampers an identification of the chromosomes by length as the lateral components may not be traced from one telomere to the other. It is, therefore, not possible to establish whether particular chromosomes are more frequently involved in multiple associations than others. The mean number of pairing partner exchanges per lateral compo-

Table II. The total lateral component (LC) complement length, paired LC length, degree of pairing, number of LC's or LC fragments and the types of associations in eleven early zygotene nuclei from wheat euhaploids of Chinese Spring. s.d., standard deviation.

\begin{tabular}{|c|c|c|c|c|c|c|c|c|}
\hline Nucleus & $\begin{array}{l}\text { Total LC } \\
\text { length } \\
(\mu \mathrm{m})\end{array}$ & $\begin{array}{l}\text { Paired LC } \\
\text { length } \\
(\mu \mathrm{m})\end{array}$ & $\begin{array}{l}\% \\
\text { pairing }\end{array}$ & $\begin{array}{l}\text { Number of } \\
\text { LC's }\end{array}$ & & $\begin{array}{l}\text { Type } \\
\text { assoc }\end{array}$ & $\begin{array}{l}\text { of } \\
\text { ations }\end{array}$ & \\
\hline EZ 1 & 2547 & 55 & 2.2 & 56 & & & & \\
\hline $\mathrm{EZ} 2$ & 1329 & 38 & 2.8 & 30 & & & & \\
\hline EZ 3 & 2123 & 66 & 3.1 & 23 & $1 \times 13$ & $1 \times 3$ & & $7 \times 1$ \\
\hline $\mathrm{EZ} 4$ & 2155 & 83 & 3.9 & 71 & & & & \\
\hline EZ 5 & 1921 & 83 & 4.3 & 29 & $1 \times 18$ & & $2 \times 2$ & $7 \times 1$ \\
\hline $\mathrm{EZ} 6$ & 1922 & 104 & 5.4 & 47 & & & & \\
\hline $\mathrm{EZ} 7$ & 1984 & 134 & 6.8 & 35 & & & & \\
\hline EZ 8 & 2226 & 153 & 6.9 & 40 & & & & \\
\hline $\mathrm{EZ} 9$ & 2536 & 207 & 8.1 & 24 & $1 \times 16$ & & $2 \times 2$ & $4 \times 1$ \\
\hline EZ 10 & 2356 & 196 & 8.3 & 33 & $1 \times 20$ & $2 \times 3$ & $3 \times 2$ & $1 \times 1$ \\
\hline $\mathrm{EZ} 11$ & 2479 & 240 & 9.7 & 26 & $1 \times 23$ & & & $3 \times 1$ \\
\hline Mean & 2225 & 132 & 5.9 & 38 & & & & \\
\hline \pm s.d. & 245 & 65 & 2.5 & 15.6 & & & & \\
\hline
\end{tabular}

'The data from EZ2 are not included in calculating the mean. 

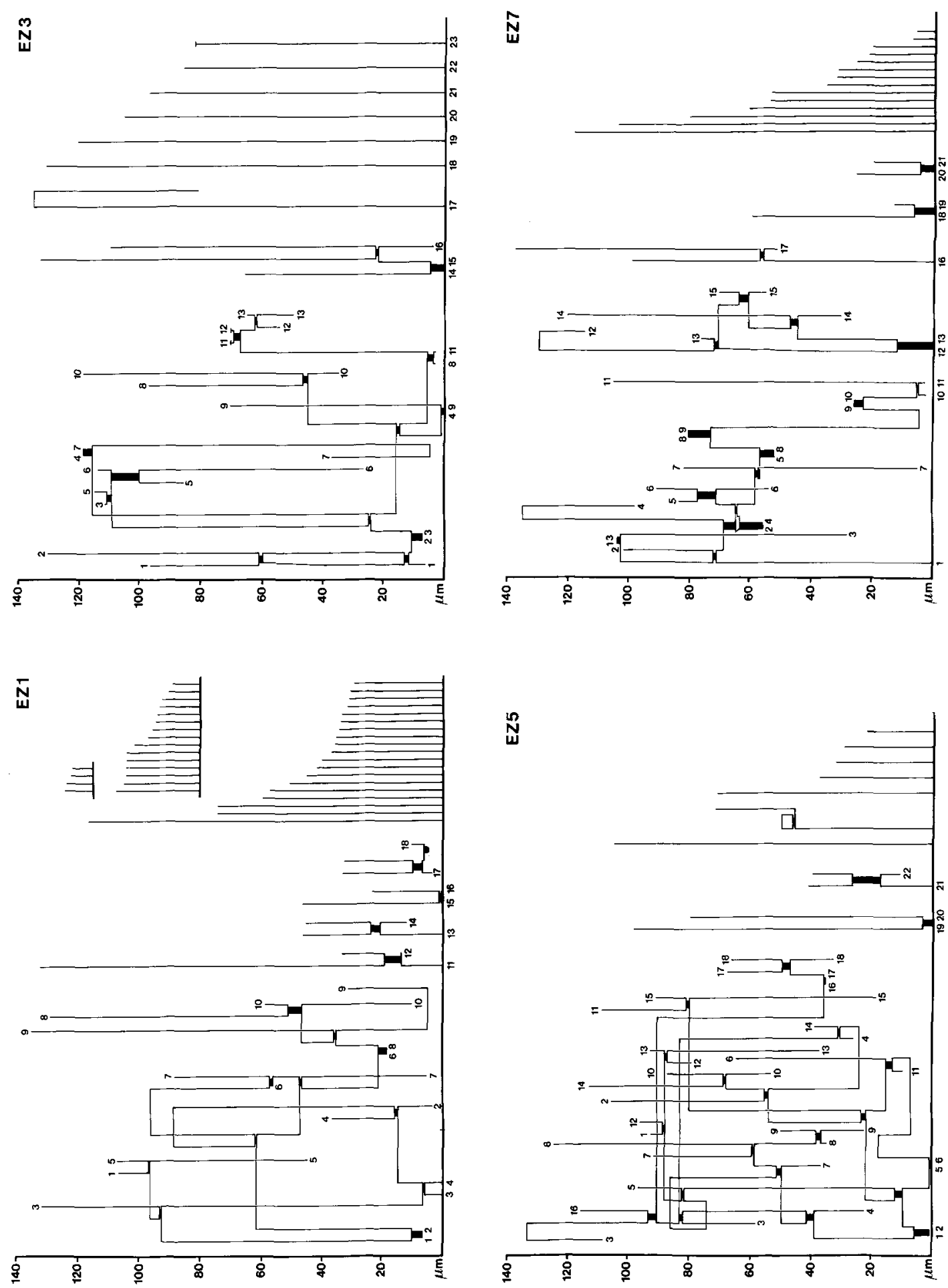
Figure 4. Idiograms of the complements of four early zygotene nuclei of euhaploid wheat (EZ1, 2.2\% pairing; EZ3, $3.1 \%$ pairing: $\mathrm{EZ} 5,4.3 \%$ pairing and $\mathrm{EZ7}, 6.8 \%$ pairing). The individual lateral components or lateral component fragments are denoted by numbers and the multiple associations are arranged according to the number of lateral components involved. The actual length of each lateral component is represented by the vertical line only.

nent engaged in synapsis in the 11 nuclei amounts to 0.72 . In a few cases, the multiple associations consisted of one or a few long lateral components which had synapsed with several other lateral components along their length, e.g. the multiple association of 18 lateral components in nucleus EZ5 where lateral component number 1 has five pairing partners, each one having one or two additional pairing partners. In other cases the multiple associations resulted
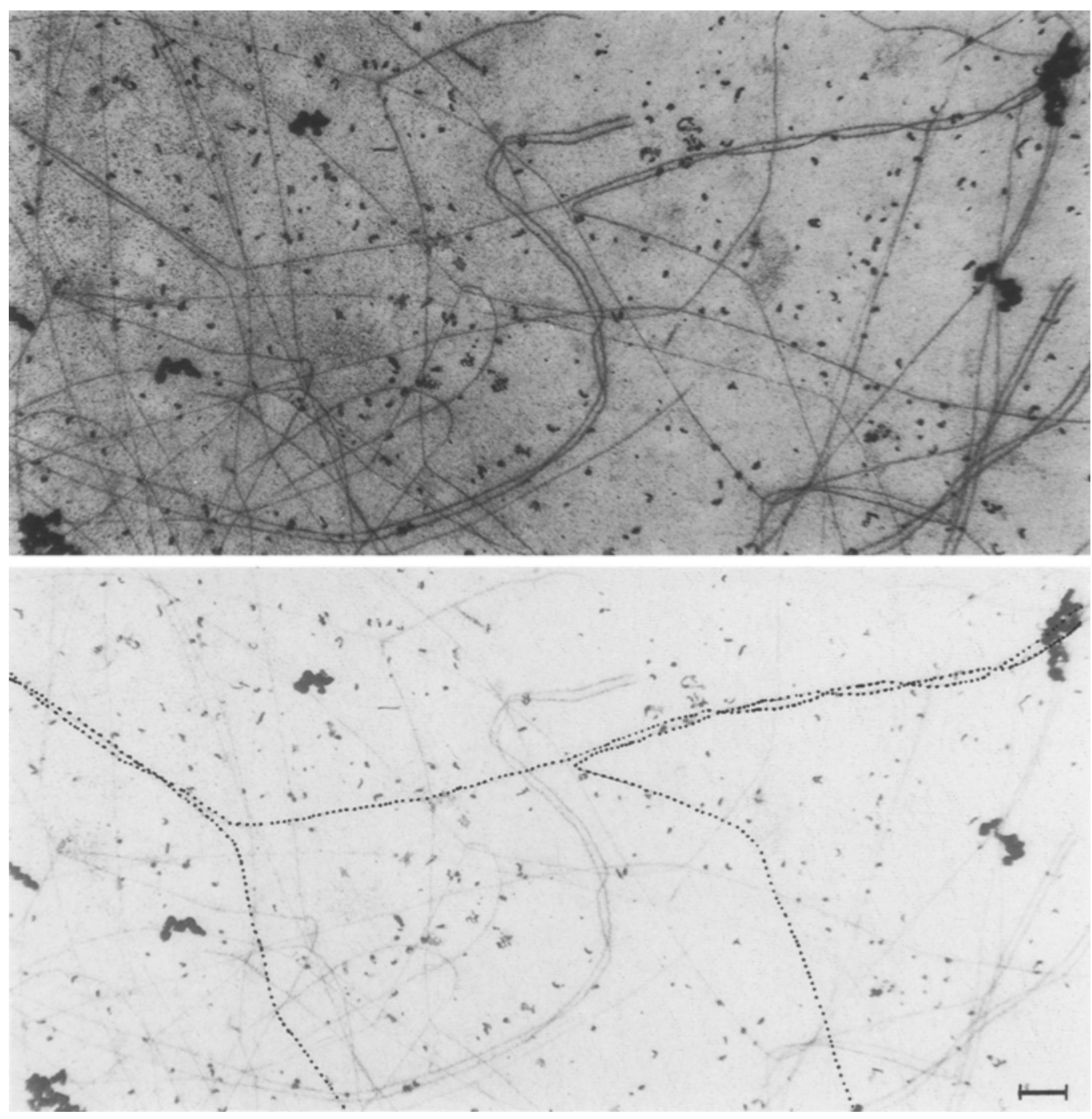

Figure 5. A micrograph and a tracing of a pairing partner exchange in an early zygotene nucleus of euhaploid wheat. $(\mathrm{Bar}=1 \mu \mathrm{m})$ 


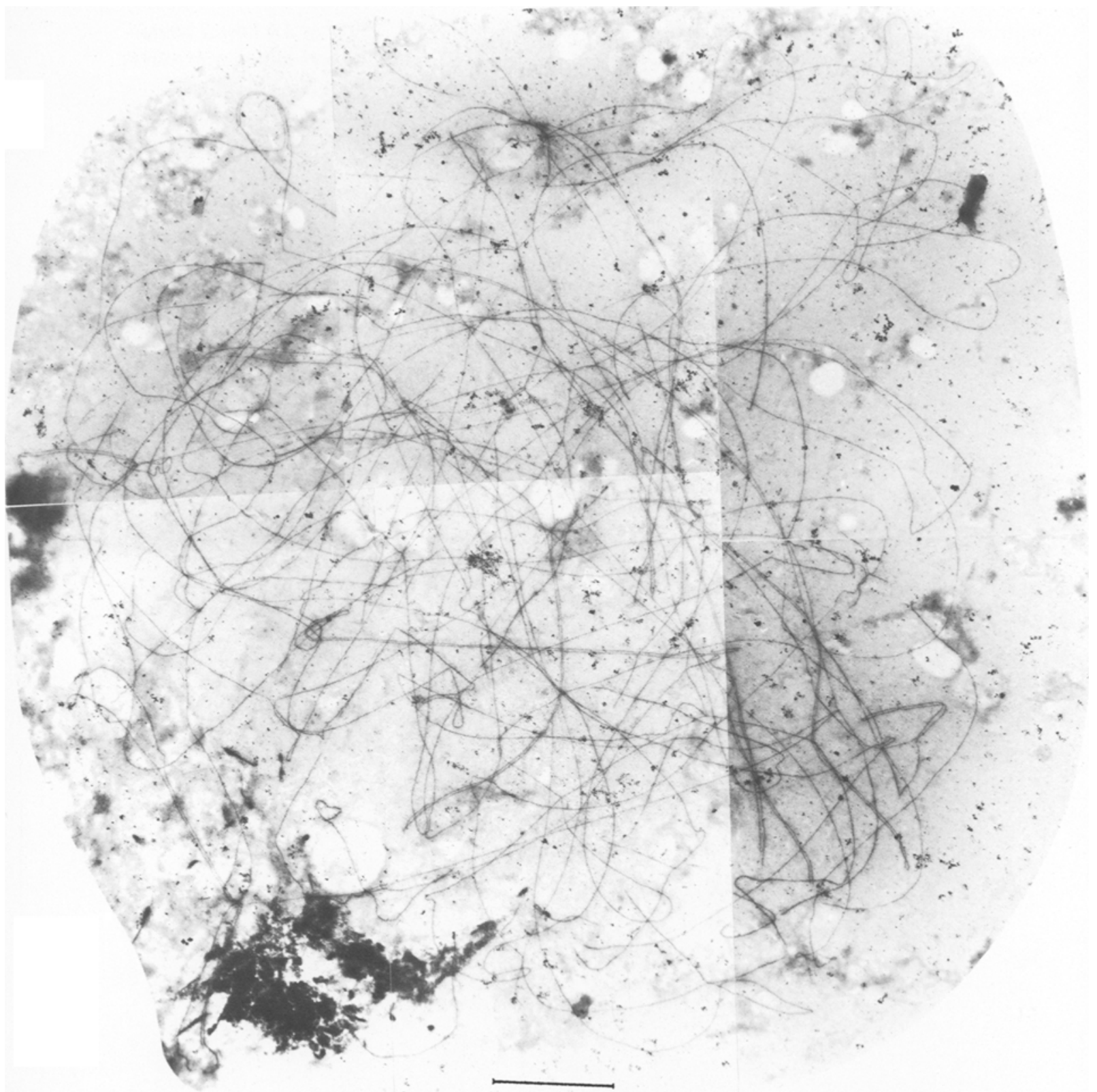


Figure 6. A montage of micrographs of a mid-late zygotene nucleus (M-LZ 6, 13.6\% pairing). (Bar $=5 \mu \mathrm{m})$

from one or few pairing partner exchanges between a large number of lateral components as exemplified by the multiple association involving 13 lateral components in nucleus EZ3 (Figure 4). In this nucleus lateral component number 1 synapses with lateral component number 2, 2 synapses with 1 and 3, 3 synapses with 2,4 and 5,4 synapses with $7,3,8$ and 9,5 synapses with 3 and 6,6 synapses with 5,7 synapses with 4,8 synapses with 10,4 and 11,11 synapses with 4,10 synapses with 8,11 synapses with 8 and 12, 12 synapses with 13, and 13 synapses with 12 . It is apparent that nearly all lateral components may exchange pairing partners as exemplified in the early zygotene nuclei with numbers of lateral components only slight- ly in excess of the chromosome number of 21. Furthermore, following an exchange of partner, there is rarely a subsequent exchange back to the original partner (e.g. lateral components 12 and 13 in nucleus EZ7) and there is at the early zygotene stage seldom more than one synaptonemal complex segment formed between any pair of lateral components.

The mean pairing percentage in the 20 traced mid to late zygotene nuclei amounted to $19.9 \%$ with a range from $10.3 \%$ to $41.3 \%$ (see Figure 6 for a montage of micrographs). Although a subdivision of this stage was not attempted, it is apparent that the nuclei with a more extensive synapsis, such as nuclei M-LZ17-20, are late zygotene nuclei. In these nuclei $30-40 \%$ of the

Table III. The total lateral component (LC) complement length, paired LC length, degree of pairing, number of LC's or LC fragments and the types of associations in twenty mid-late zygotene nuclei from wheat euhaploids of Chinese Spring. s.d., standard deviation.

\begin{tabular}{|c|c|c|c|c|c|c|c|c|c|}
\hline \multirow{2}{*}{$\begin{array}{l}\text { Nucleus } \\
\text { M-LZ } 1\end{array}$} & \multirow{2}{*}{$\begin{array}{l}\begin{array}{l}\text { Total LC } \\
\text { length } \\
(\mu \mathrm{m})\end{array} \\
2643\end{array}$} & \multirow{2}{*}{$\begin{array}{l}\begin{array}{l}\text { Paired LC } \\
\text { length } \\
(\mu \mathrm{m})\end{array} \\
272\end{array}$} & \multirow{2}{*}{$\begin{array}{l}\begin{array}{l}\% \\
\text { pairing }\end{array} \\
10.3\end{array}$} & \multicolumn{2}{|l|}{$\begin{array}{l}\text { Number of } \\
\text { LC's }\end{array}$} & \multicolumn{3}{|c|}{$\begin{array}{l}\text { Types of } \\
\text { associations }\end{array}$} & \multirow[b]{2}{*}{$7 \times 1$} \\
\hline & & & & 32 & $1 \times 9$ & $1 \times 8$ & & $4 \times 2$ & \\
\hline M-LZ 2 & 1727 & 186 & 10.8 & 29 & $1 \times 8$ & $1 \times 4$ & $1 \times 3$ & $2 \times 2$ & $10 \times 1$ \\
\hline M-LZ 3 & 1748 & 206 & 11.8 & 41 & & & & & \\
\hline M-LZ 4 & 2610 & 311 & 11.9 & 62 & & & & & \\
\hline M-LZ 5 & 1927 & 256 & 13.3 & 65 & & & & & \\
\hline M-LZ 6 & 2254 & 306 & 13.6 & 49 & & & & & \\
\hline M-LZ 7 & 1698 & 236 & 13.9 & 46 & & & & & \\
\hline M-LZ 8 & 1991 & 297 & 14.9 & 39 & & & & & \\
\hline $\mathrm{M}-\mathrm{LZ} 9$ & 1921 & 308 & 16.0 & 48 & & & & & \\
\hline M-LZ 10 & 1929 & 311 & 16.1 & 43 & & & & & \\
\hline M-LZ 11 & 2165 & 375 & 17.3 & 52 & & & & & \\
\hline M-LZ 12 & 2230 & 395 & 17.7 & 73 & & & & & \\
\hline M-LZ 13 & 2151 & 472 & 22.0 & 75 & & & & & \\
\hline M-LZ 14 & 2250 & 528 & 23.5 & 48 & & & & & \\
\hline M-LZ 15 & 2283 & 537 & 23.5 & 34 & $1 \times 11$ & $1 \times 6$ & $1 \times 4$ & $3 \times 2$ & $7 \times 1$ \\
\hline M-LZ 16 & 2249 & 533 & 23.7 & 49 & & & & & \\
\hline M-LZ 17 & 2085 & 611 & 29.3 & 53 & & & & & \\
\hline M-LZ 18 & 2190 & 709 & 32.0 & 35 & $1 \times 20$ & & $1 \times 3$ & $2 \times 2$ & $8 \times 1$ \\
\hline M-LZ 19 & 2728 & 973 & 35.7 & 35 & $1 \times 7$ & & $3 \times 3$ & $5 \times 2$ & $9 \times 1$ \\
\hline M-LZ 20 & 1537 & 634 & 41.3 & 45 & & & & & \\
\hline Mean & 2116 & 423 & 19.9 & 48 & & & & & \\
\hline \pm s.d. & 318 & 200 & 8.8 & 13 & & & & & \\
\hline
\end{tabular}




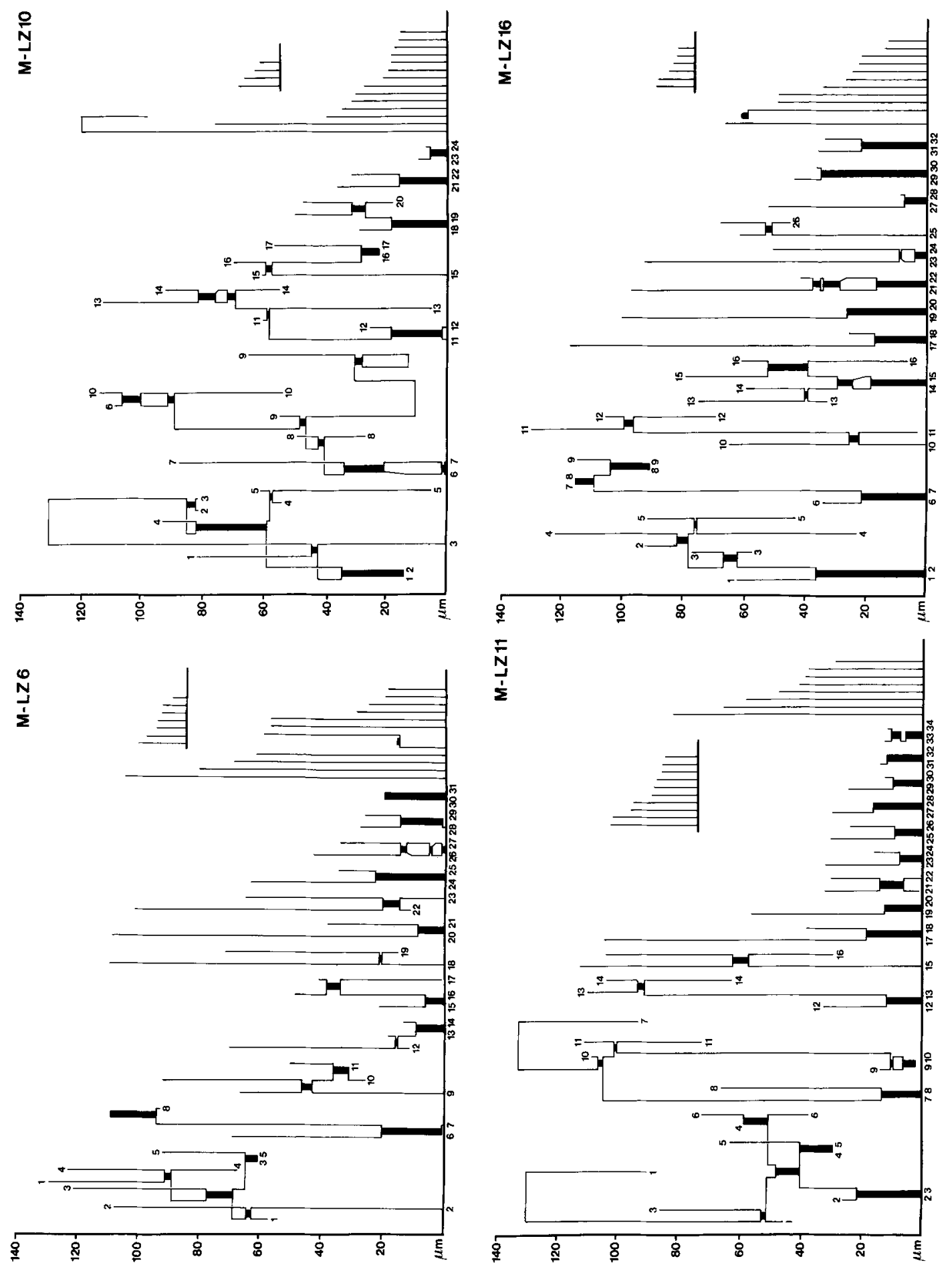



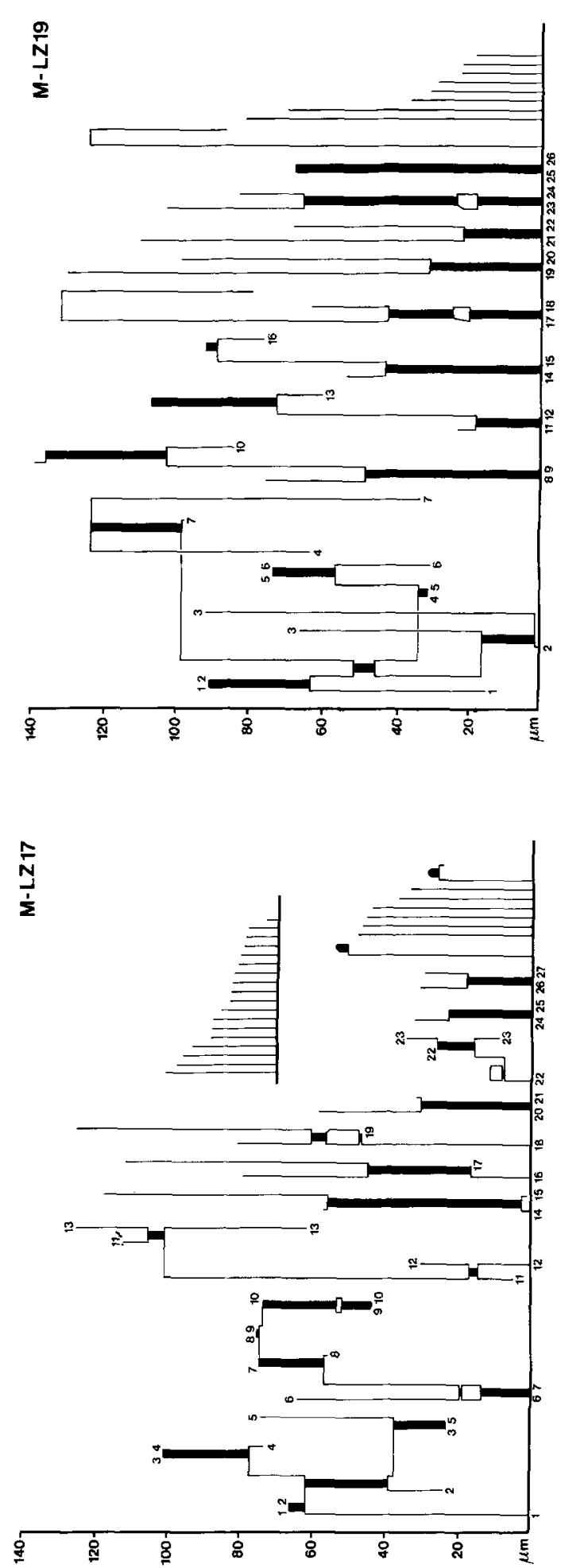

Figure 7. Idiograms of the lateral component complement of six mid-late zygotene nuclei (M-LZ6, 13.6\%, M-LZ10, $16.1 \%$ pairing, M-LZ11, 17.3\% pairing, M-LZ16, 23.7\% pairing, M-LZ17, 29.3\% pairing, M-LZ19, 35.7\% pairing). For explanation of symbols see legend to Figure 4.

complement had synapsed and the length of the synaptonemal complexes was from $611-973 \mu \mathrm{m}$ (Table III), which is close to the synaptonemal complex length at early diplotene (mean of 615 $\mu \mathrm{m}$, see section 3.5). The mean number of lateral components or lateral component fragments found in these nuclei was 48 (Table III), i.e. slightly more than twice the number of chromosomes. At this stage the multiple associations were less complex than at the preceding stage. In five of the nuclei where the number of lateral components was below 35 , only one nucleus had a multiple association of 20 lateral components while in the remaining four nuclei the maximium number of lateral components in a multiple association was eleven. Although pairing partner exchanges still are frequent (Figures 8 and 9) it is apparent from the quantitative data in Table III, and the idiograms in Figure 7 that several associations now only involve two or three lateral components. The kinetics of synaptonemal complex formation during the progression of synapsis is also clearly illustrated by the data in Table IV. While synaptonemal complex formation is primarily initiated interstitially at early zygotene, synaptonemal complex formation at mid zygotene predominantly involves the telomeres. In nuclei with more than $15 \%$ of the complement synapsed about half of all synaptonemal complex segments involve telomeres, the length of these segments accounting for two-thirds of the total synaptonemal complex length. The total number of segments remains relatively constant from a pairing range of $5-10 \%$ to more than $25 \%$ synapsis while the number of lateral components in multiple associations decreases. During the progression of synapsis there is thus a synaptic correction whereby interstitial synaptonemal complex segments are removed by dissolution of the central region while in most cases new central regions 

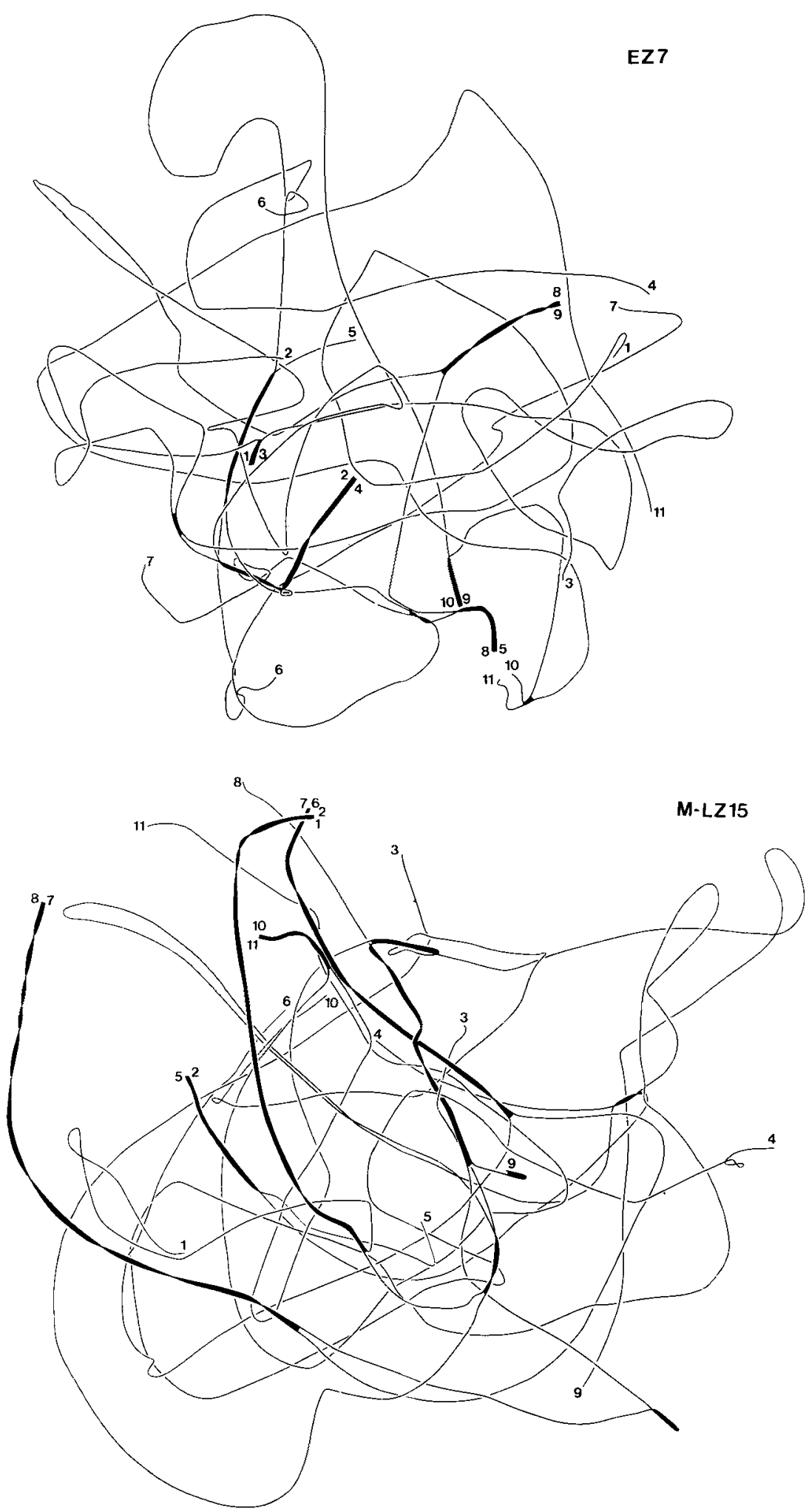
Figure 8. Tracings of multiple associations from zygotene nuclei of euhaploid wheat. In Figure 8a is shown an association of eleven lateral components from the early zygotene nucleus EZ 7. In Figure $8 \mathrm{~b}$ is shown an association of eleven lateral components from the mid-late zygotene nucleus M-LZ15.

combine lateral components which are already partially synapsed with each other. This results in an elimination of pairing partner exchanges from early zygotene to mid zygotene. In the range from $0-10 \%$ synapsis there is a mean of 0.72 pairing partner exchanges per lateral component involved in synapsis while the corresponding number in the pairing range of $10-20 \%$
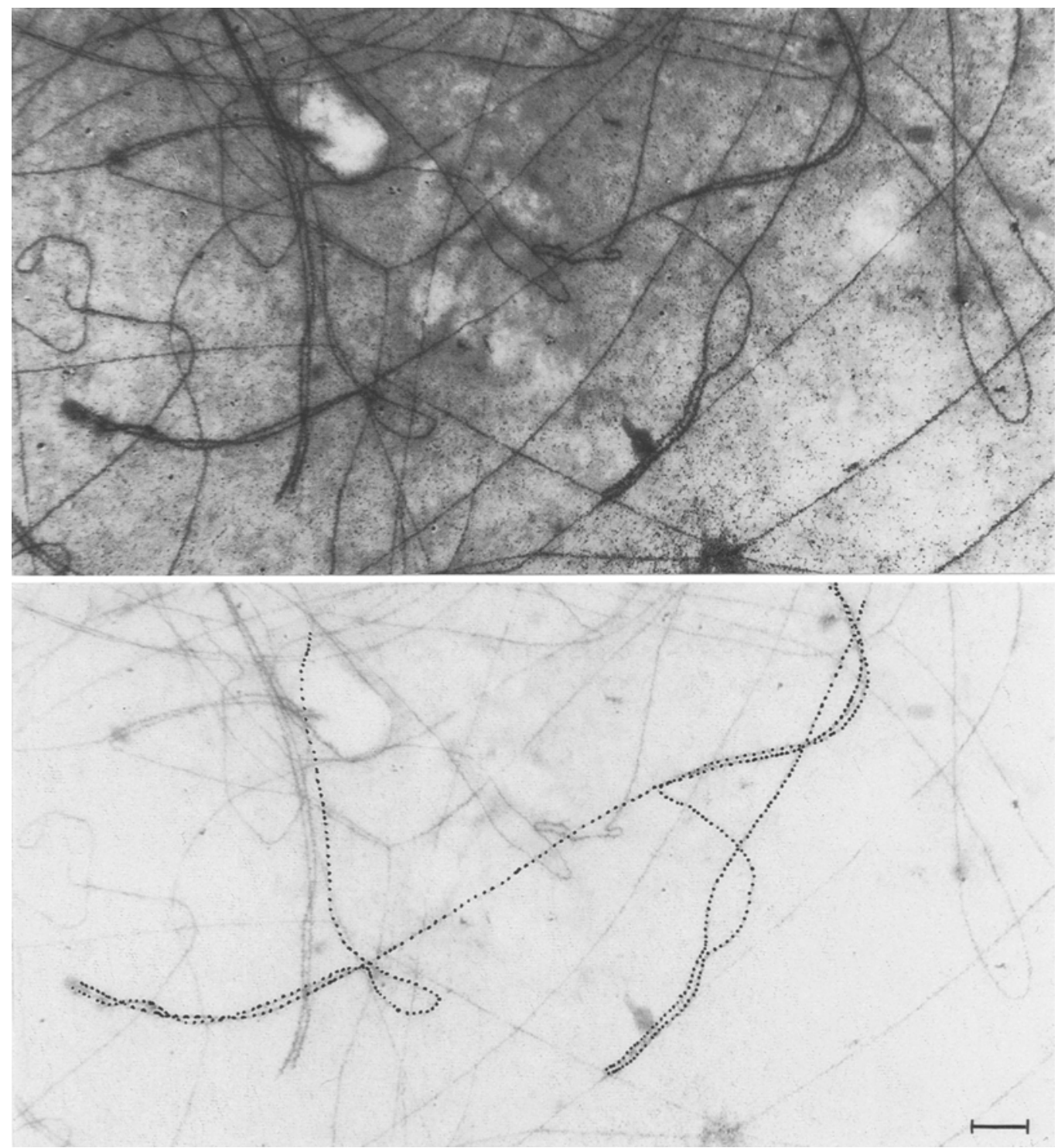

Figure 9. A micrograph and a tracing of an exchange of pairing partners in a mid-late zygotene nucleus. (Bar $=$ $1 \mu \mathrm{m})$ 
Table IV. Mean number and length of synaptonemal complex (SC) segments, mean number of SC segments involving telomeres, the ratio between the length of SC segments involving telomeres and total SC length and mean number of pairing partner exchanges per LC involved in synapsis at different stages of synapsis in 31 zygotene nuclei from wheat euhaploids of Chinese Spring.

\begin{tabular}{lllllll}
\hline $\begin{array}{l}\text { Pairing } \\
\text { percent }\end{array}$ & $\begin{array}{l}\text { Number } \\
\text { of } \\
\text { nuclei }\end{array}$ & $\begin{array}{l}\text { Mean } \\
\text { length } \\
\text { of SC } \\
\text { segments }\end{array}$ & $\begin{array}{l}\text { Mean } \\
\text { number } \\
\text { of SC } \\
\text { segments }\end{array}$ & $\begin{array}{l}\text { Mean } \\
\text { number } \\
\text { of SC } \\
\text { segments } \\
\text { involving } \\
\text { telomeres }\end{array}$ & $\begin{array}{l}\text { Length of SC } \\
\text { segments in } \\
\text { telomeres } \\
\text { of total SC } \\
\text { length }\end{array}$ & $\begin{array}{l}\text { Number of } \\
\text { pairing } \\
\text { partner } \\
\text { exchanges } \\
\text { per LC }\end{array}$ \\
\hline $0-5$ & 5 & & 2.4 & 21.4 & 0.62 \\
$5-10$ & 6 & 3.6 & 18 & 7.0 & 40.7 & 0.81 \\
$10-15$ & 8 & 6.9 & 25 & 8.9 & 66.9 & 0.40 \\
$15-20$ & 4 & 12.6 & 21 & 10.3 & 67.5 & 0.32 \\
$20-25$ & 4 & 15.8 & 22 & 12.8 & 72.7 & 0.38 \\
$25-$ & 4 & 19.5 & 27 & 13.0 & 64.6 & 0.42 \\
\hline
\end{tabular}
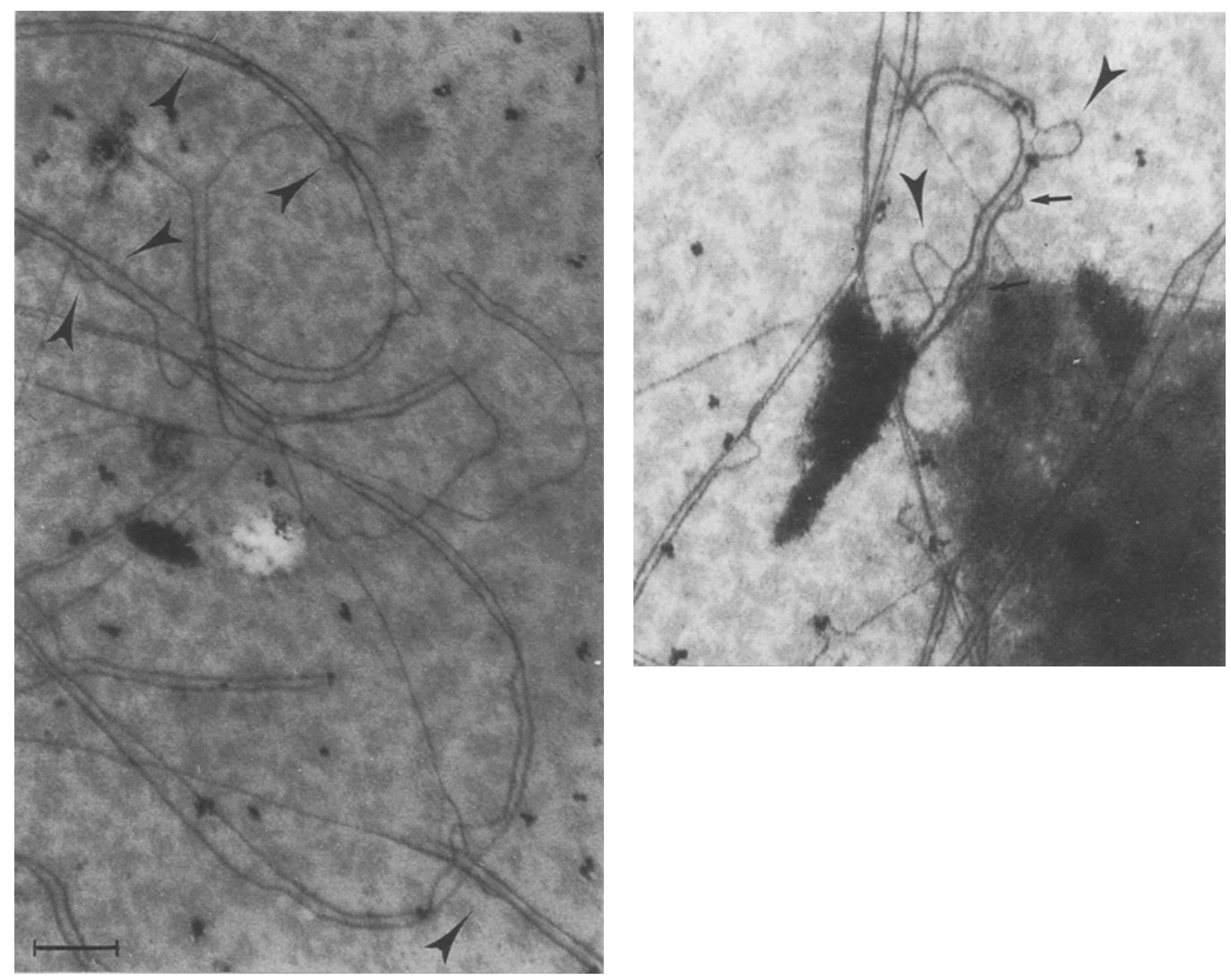

Figure 10. Two micrographs of an aberrant euhaploid nucleus showing splitting of the lateral components (arrowheads). Cases where a lateral component is split into more than two subunits are denoted by arrows. (Bar = $1 \mu \mathrm{m})$ 
Table V. The total lateral component (LC) complement length, paired LC complex (SC) length, degree of pairing, number of $L C$ 's or $L C$ fragments and the types of associations in six zygotene nuclei from wheat euhaploids of $T$. aestivum cv. Kedong. s.d., standard deviation.

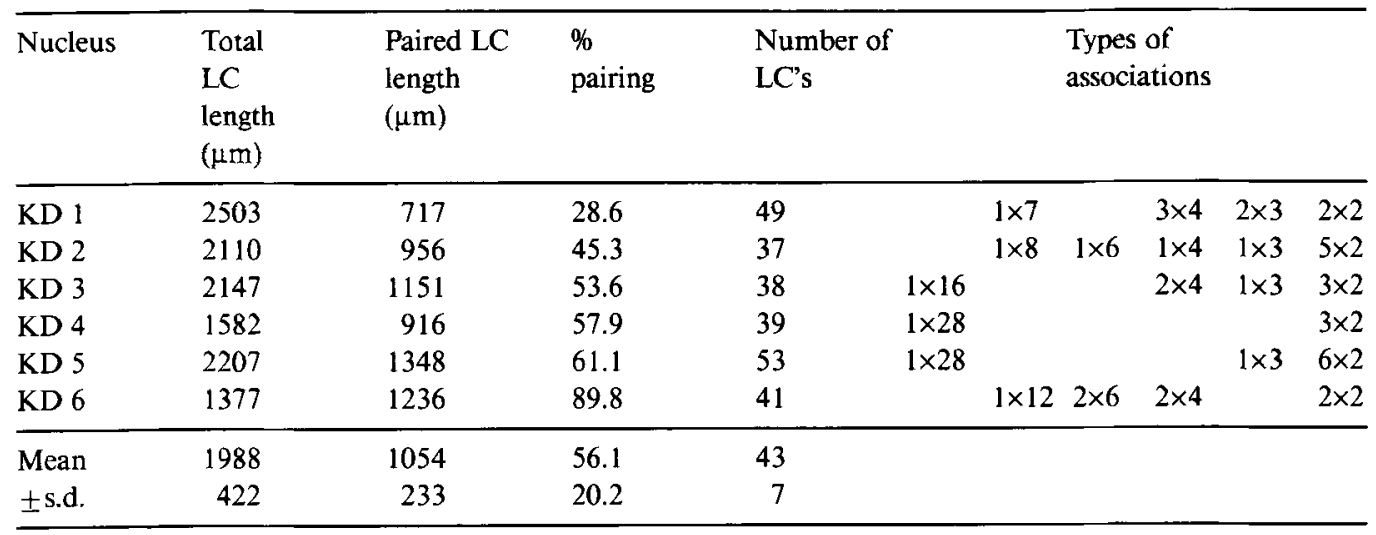

is 0.36 and 0.40 in nuclei with more than $20 \%$ synapsis (Table IV).

At early zygotene and mid-late zygotene the combined lateral component length amounts to $2225 \mu \mathrm{m}$ and $2116 \mu \mathrm{m}$. This is basically the same as half the lateral complement length in allohexaploid wheat at early-mid zygotene (1984 $\mu \mathrm{m}$, (9)), showing that haploidy is not accompanied by changes in the lateral component length at meiosis.

During the course of this stage no differences were found with respect to synapsis between different plants. In one plant, however, two of twenty nuclei from the same spike deviated in the structure of the lateral components which often were split into two or three strands (Figure 10). Tracings of the complements of one late zygotene nucleus ( $41.4 \%$ pairing) revealed that all 29 lateral components or lateral component fragments were involved in one multiple association and the complement length was only 1257 $\mu \mathrm{m}$ compared to a mean of $2116 \mu \mathrm{m}$ in the normal appearing nuclei.

A number of nuclei from euhaploid pollen plants derived from euploid Chinese Spring wheat were also spread and analyzed. No differences in synapsis were encountered between these plants and those obtained from monosomic 5B Chinese Spring wheat. The analysis also included a study of a large number of nuclei from euhaploids regenerated from anthers of the Chinese winter wheat variety Kedong. Six nuclei were analyzed in detail (Table V and Figure 11). The mean complement length amounted to $1988 \mu \mathrm{m}$ which is almost the same as in euhaploids derived from Chinese Spring wheat. Also the frequency of pairing partner exchange appeared to be the same as in Chinese Spring haploids, and up to 28 lateral components or lateral component fragments were involved in the same multiple association. Synaptonemal complex formation appeared, however, to be more extensive in the Kedong genotype where up to $90 \%$ of the complement had synapsed.

\subsection{Synapsis in nullisomic 5B haploids}

The generation of haploids nullisomic for chromosome $5 \mathrm{~B}$ by cultivation of anthers from monosomic 5B Chinese Spring wheat met with several difficulties as only one such plant reached the tillering stage. Additional nullisomic 5B plants were identified by chromosome counts and N-banding but these plants died before tillers were formed. As some of the eight 40-chromosome plants obtained were nullisomic for chromosome $5 \mathrm{~B}(10)$, it is apparent that nullisomic 5B haploids obtained by anther culture are prone to chromosome doubling at an early stage.

As outlined in section 3.1 the nullisomic 5B haploid plant only possessed few and partially empty anthers. Most of the anthers were used for light microscopy or were fixed and embedded in 


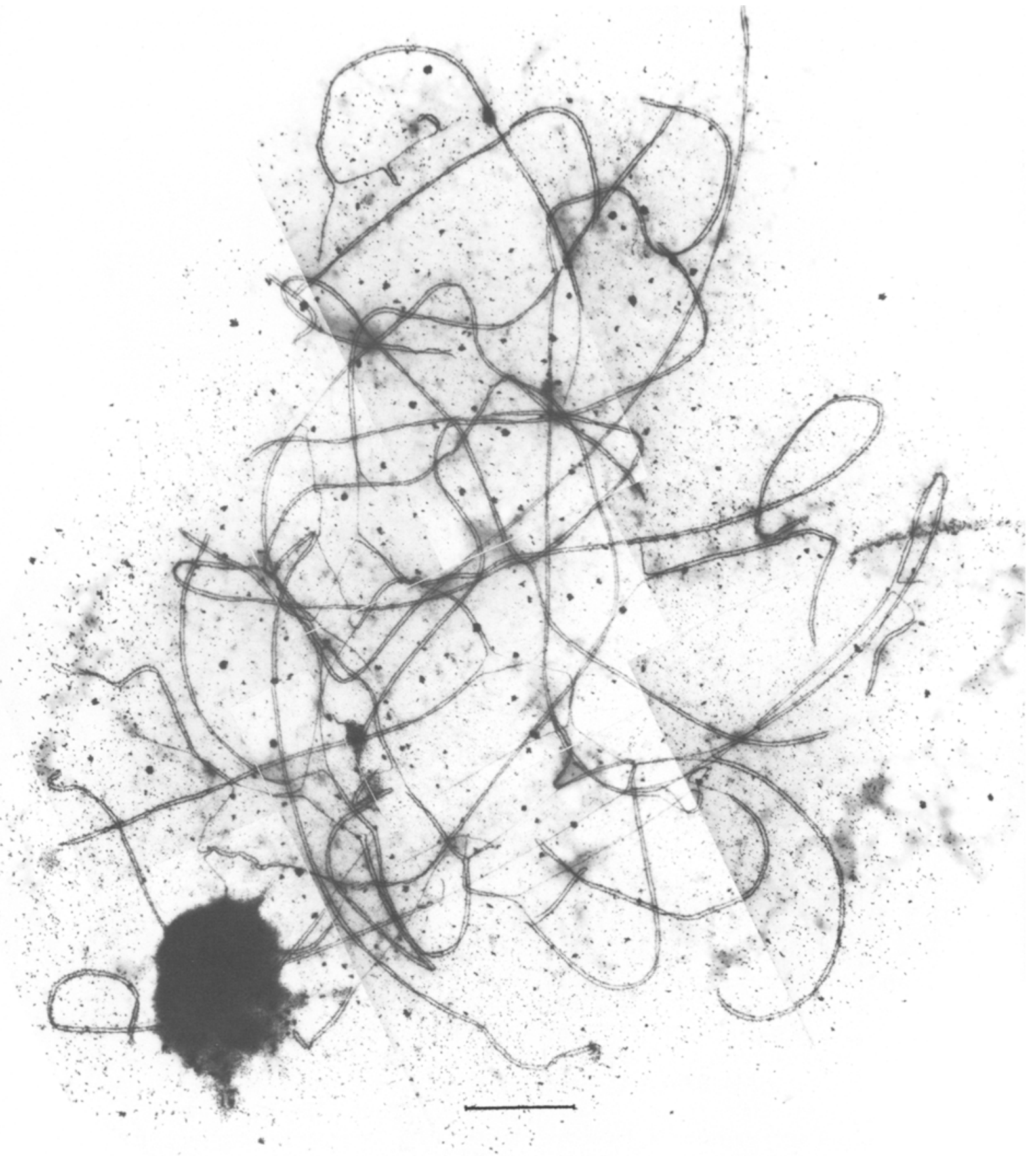

Figure 11. A montage of micrographs of a late zygotene nucleus ( $89.8 \%$ pairing) of euhaploid wheat of the variety Kedong. $(\mathrm{Bar}=5 \mu \mathrm{m})$ 


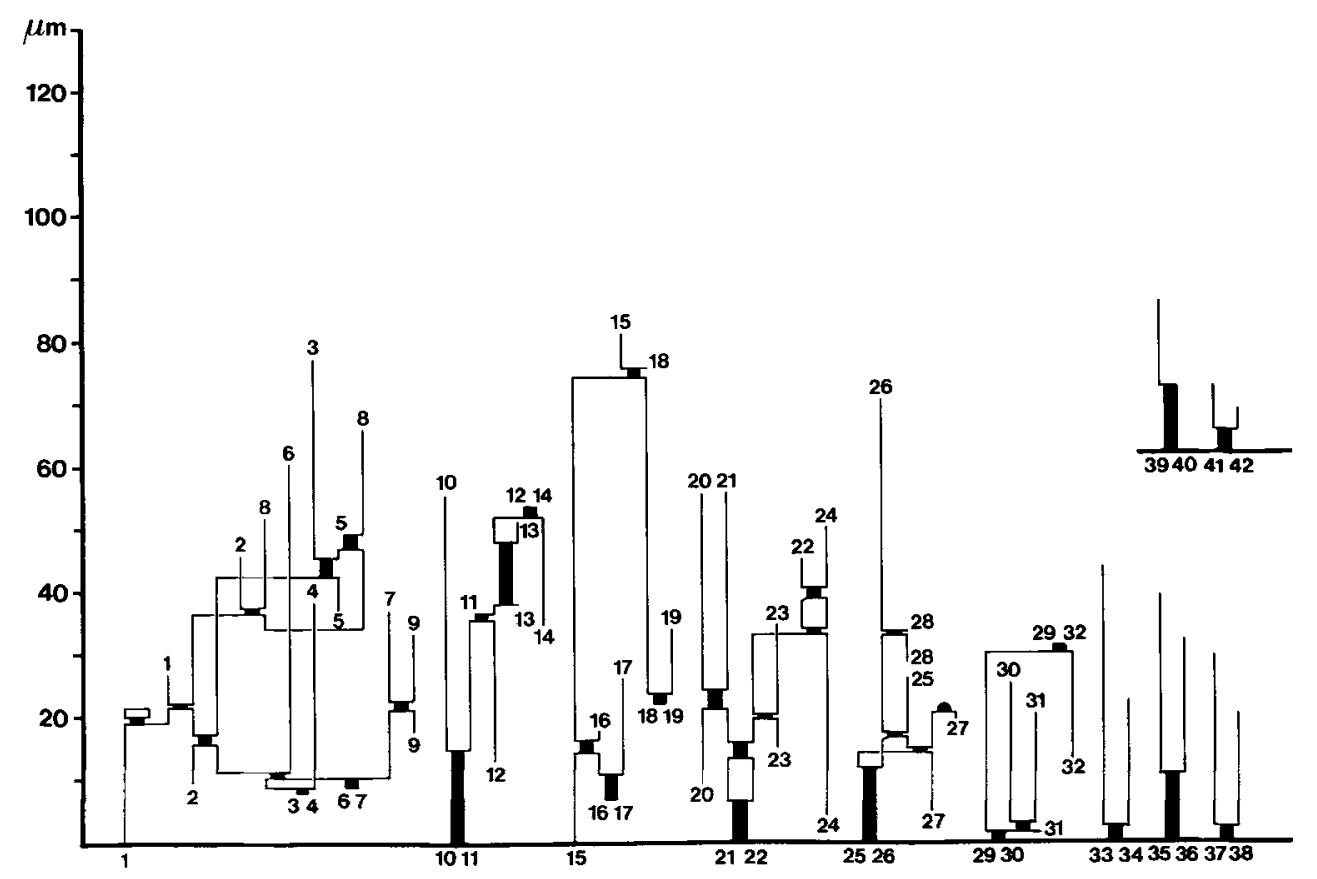

20-2

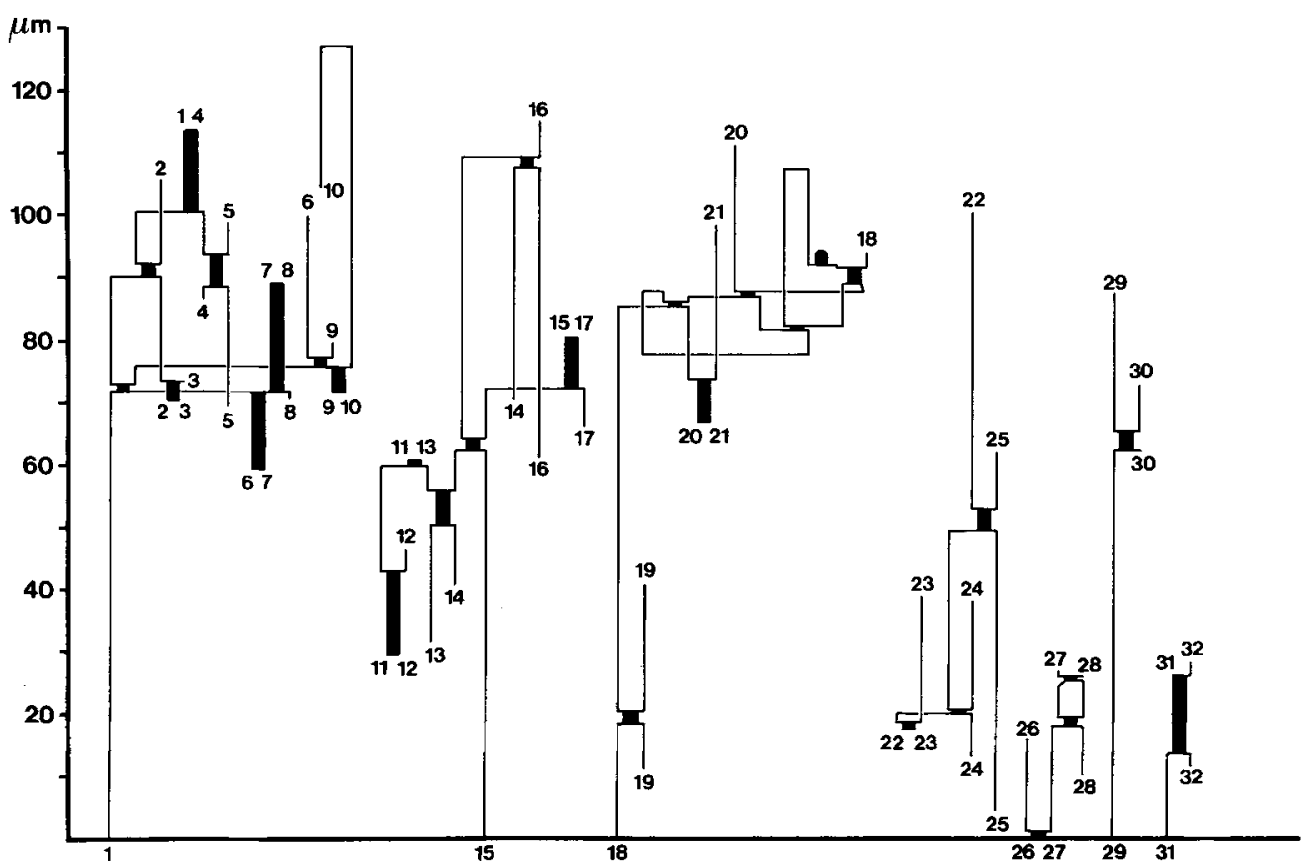

Figure 12. Idiograms of two traced zygotene nuclei of haploid wheat, nullisomic for chromosome $5 B(20-1,13.4 \%$ pairing and 20-2, 15.4\% pairing). For explanation of symbols see legend to Figure 4. 

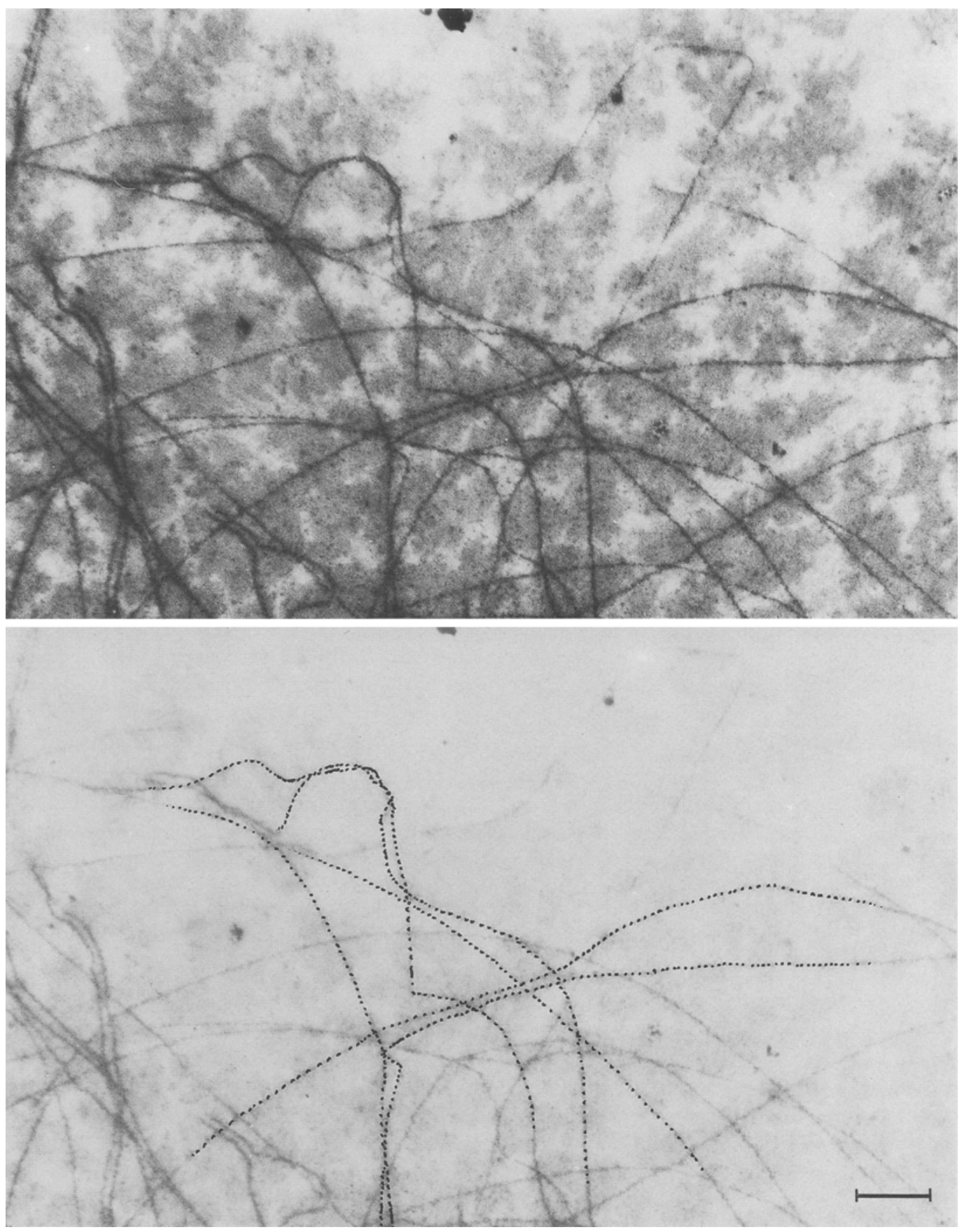

Figure 13. A micrograph and a tracing showing pairing partner exchanges in a spread zygotene nucleus of haploid wheat, nullisomic for chromosome 5B. $(\mathrm{Bar}=1 \mu \mathrm{m})$ 
Table VI. A comparision of the pairing characteristics observed in two nuclei of nullisomic $5 B$ haploid wheat and six euhaploid nuclei at a similar stage of pairing.

\begin{tabular}{|c|c|c|c|c|c|c|}
\hline Nuclei & $\begin{array}{l}\% \\
\text { pairing }\end{array}$ & $\begin{array}{l}\mathrm{LC} \\
\text { asso } \\
\text { inv } \\
\text { mo } \\
\text { thre } \\
\mathrm{Nu}\end{array}$ & $\begin{array}{l}\text { tions } \\
\text { ng } \\
\text { han } \\
\text { C's } \\
\text { r \% }\end{array}$ & $\begin{array}{l}\text { Number } \\
\text { of SC } \\
\text { segments }\end{array}$ & $\begin{array}{l}\text { Mean } \\
\text { length of } \\
\text { each SC } \\
\text { segment } \\
(\mu \mathrm{m})\end{array}$ & $\begin{array}{l}\text { Number of } \\
\text { pairing } \\
\text { partner } \\
\text { exchanges } \\
\text { per LC }\end{array}$ \\
\hline Mean 1 & 13.6 & 9 & $16 \%$ & 20 & 13.5 & 0.20 \\
\hline $20-1$ & 13.4 & 32 & $48 \%$ & 39 & 6.0 & 0.57 \\
\hline Mean 2 & 15.7 & 14 & $31 \%$ & 24 & 13.0 & 0.51 \\
\hline $20-2$ & 15.4 & 25 & $52 \%$ & 30 & 8.6 & 0.56 \\
\hline
\end{tabular}

Mean 1: The data are from three euhaploid nuclei at $13.3 \%, 13.6 \%$ and $13.9 \%$ pairing, respectively. Mean 2: The data are from three euhaploid nuclei at $14.9 \%, 16.0 \%$ and $16.1 \%$ pairing, respectively. 20-1 and 20-2: Two nuclei are from the haploid nullisomic for chromosome 5B.

resin for sectioning and electron microscopy, and only a few anthers were processed for spreading. A total of six analyzable nuclei were obtained and of these only two were studied and traced in detail (Figures 12 and 13). In the one nucleus the pairing percentage was $13.4 \%$ and in the other nucleus it was $15.4 \%$. A comparison of the pairing characterstics of these two nuclei and those of euhaploid nuclei displaying the same degree of synapsis (Table VI) revealed that the less paired nullisomic 5B nucleus had nearly three times as many pairing partner exchanges per lateral component and more than three times as many lateral components in associations involving more than three lateral components, than euhaploid nuclei at the same stage of synapsis. In the other nucleus there was a nearly twofold increase in the number of lateral components in multiple associations involving more than three lateral components, while there was roughly the same number of pairing partner exchanges per lateral component as in the euhaploid nuclei. Using the mean number of pairing partner exchanges in euhaploid nuclei with $10-20 \%$ synapsis a nearly twofold difference was found $(0.36$ versus 0.57 and 0.56 pairing partner exchanges per lateral component) between the two materials.

\subsection{Diplotene}

In euallohexaploid $T$. aestivum a pachytene stage can be identified, being characterized by an almost complete pairing, a change in shape of the spread nuclei from circular to elongated and a reduction in complement length by one third (8). A similar stage could not be identified in haploid wheat where the microsporocyte develops from the zygotene stage directly into diplotene. A total of 37 nuclei from euhaploid plants derived from monoisosomic $5 B$ donor plants was analyzed and assigned to an early, a mid and a late diplotene stage. Degradation of the lateral components and synaptonemal complexes appeared to proceed as in allohexaploid $T$. aestivum and the same stage characteristics were therefore applied. Nuclei at early diplotene are characterized by the initiation of degradation while at late diplotene the synaptonemal complexes are degraded into short distinct segments. Twenty and nine nuclei were assigned to these stages while the remaining eight nuclei, possessing intermediate characteristics, were denoted mid diplotene nuclei.

The fine structure of an early diplotene nucleus is shown in Figure 14. Apart from the initiation of lateral component degradation such nuclei share other ultrastructural characteristics of late zygotene nuclei. Shifts of pairing partners are easily found (Figures 15 and 16), as at zygotene there are often differences in length of the lateral components of interstitially unpaired segments, and loops and foldback pairing are occasionally seen (Figures 17 and 18). During this stage the complement length is reduced 


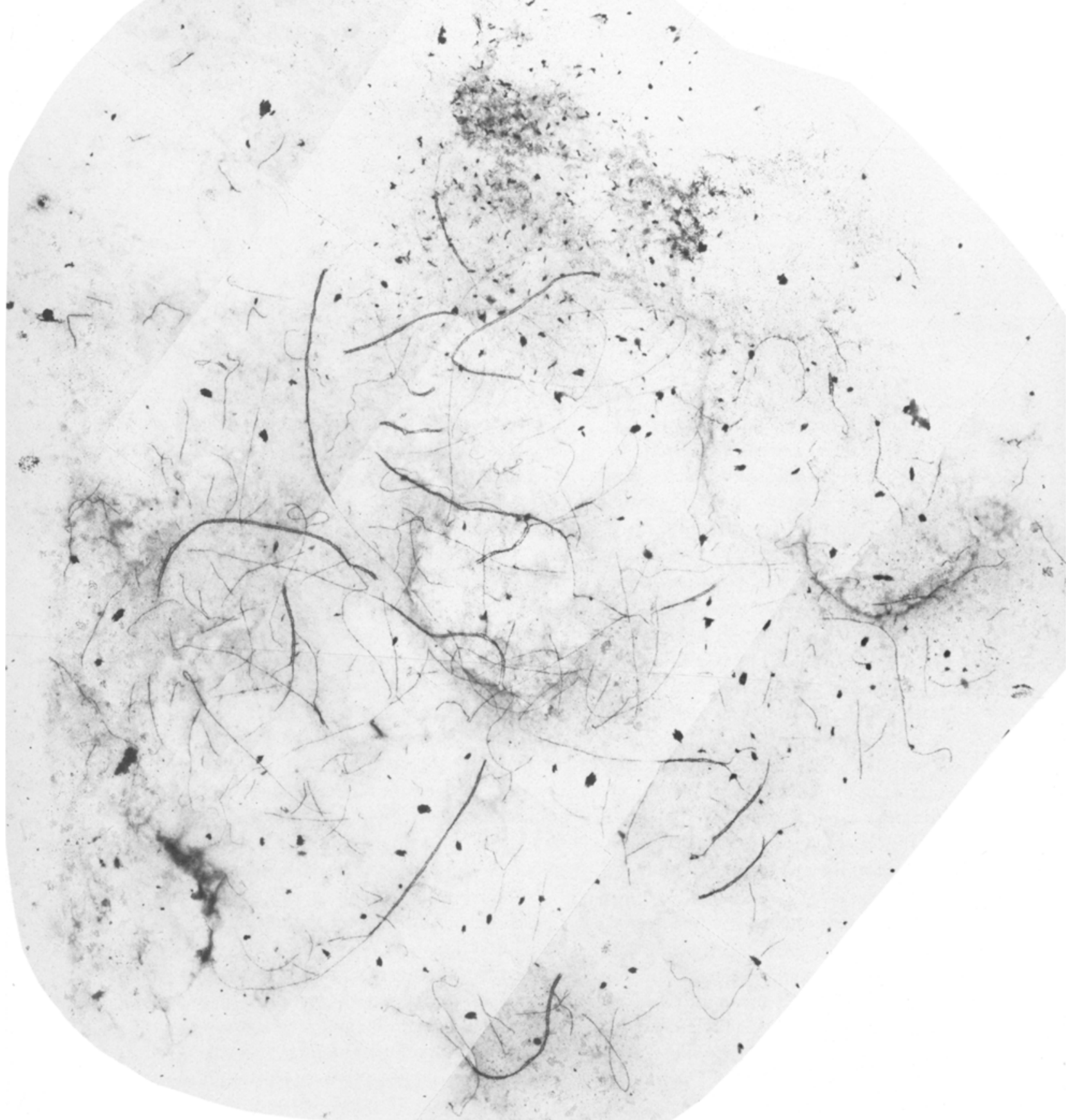

Figure 14. A montage of micrographs of an early diplotene nucleus of euhaploid wheat. (Bar $=5 \mu \mathrm{m}$ ) 

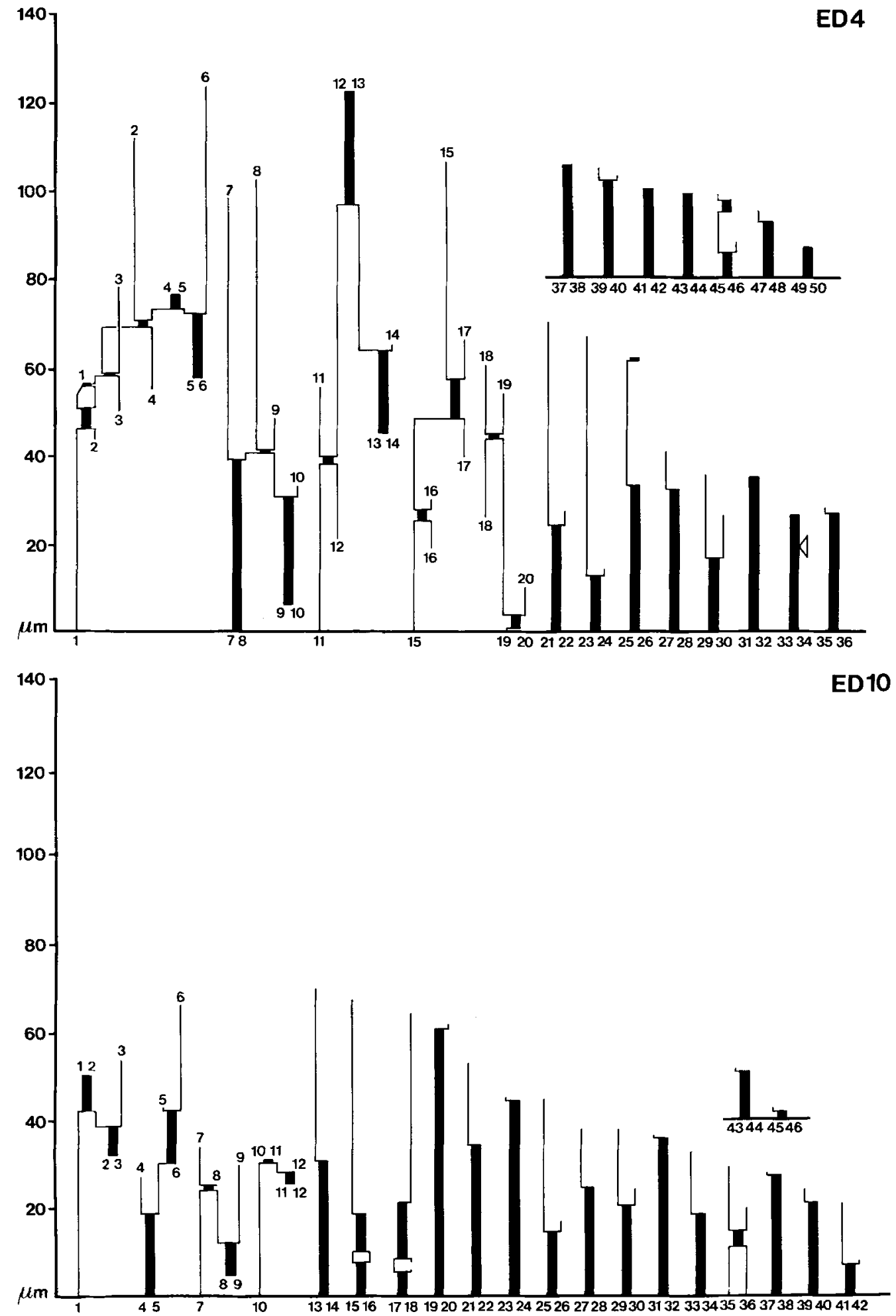

Figure 15. Idiograms of the lateral component and synaptonemal complex complements of two early diplotene nuclei of euhaploid wheat. For explanation of symbols see legend to Figure 4. 

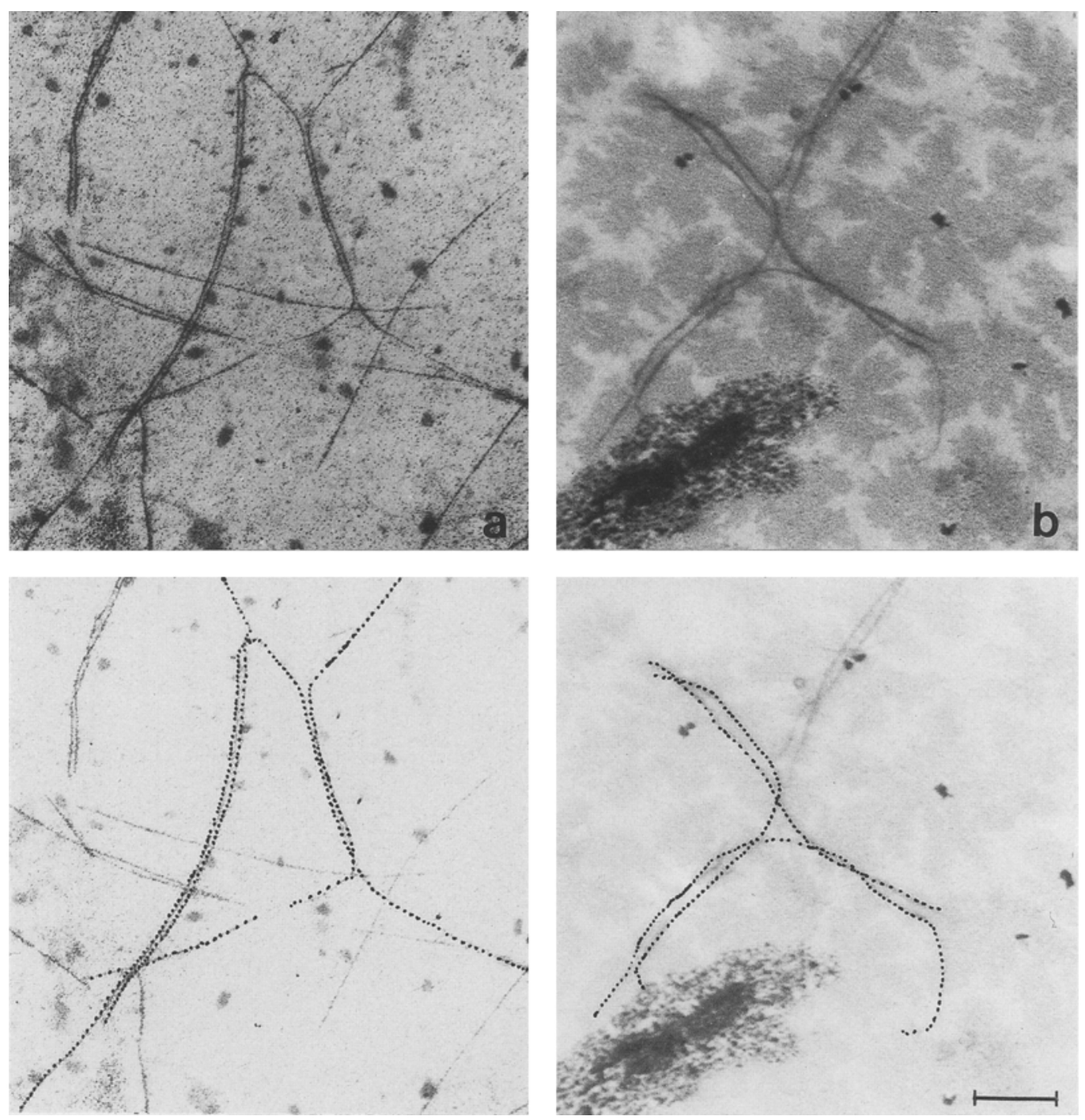

Figure 16. Two micrographs and tracings showing pairing partner exchanges in nuclei of early diplotene in euhaploid wheat. (Bar $=1 \mu \mathrm{m})$

drastically (Table VII), the mean complement length amounting to $1753 \mu \mathrm{m}$. Thirty-five percent of the retained lateral component complements was synapsed, i.e. basically the same as that achieved at the end of zygotene. Taking the early diplotene nuclei with a complement length above $2000 \mu \mathrm{m}$ (Table VII) as representatives for nuclei at the zygotene to early diplotene transition, the pairing percentage is measured to be $39 \%$. It can be concluded that in euhaploid wheat derived from Chinese Spring wheat by anther culture, synapsis stops when about 35 $40 \%$ of the complement is paired.

At mid diplotene degradation has proceeded, generating a mean of 57 synaptonemal complex segments (Table VIII). Multiple associations are still identifiable at this stage. In late diplotene nuclei (Figure 19) the mean number of synaptonemal complex segments (53 segments) was basically the same as at mid diplotene although 

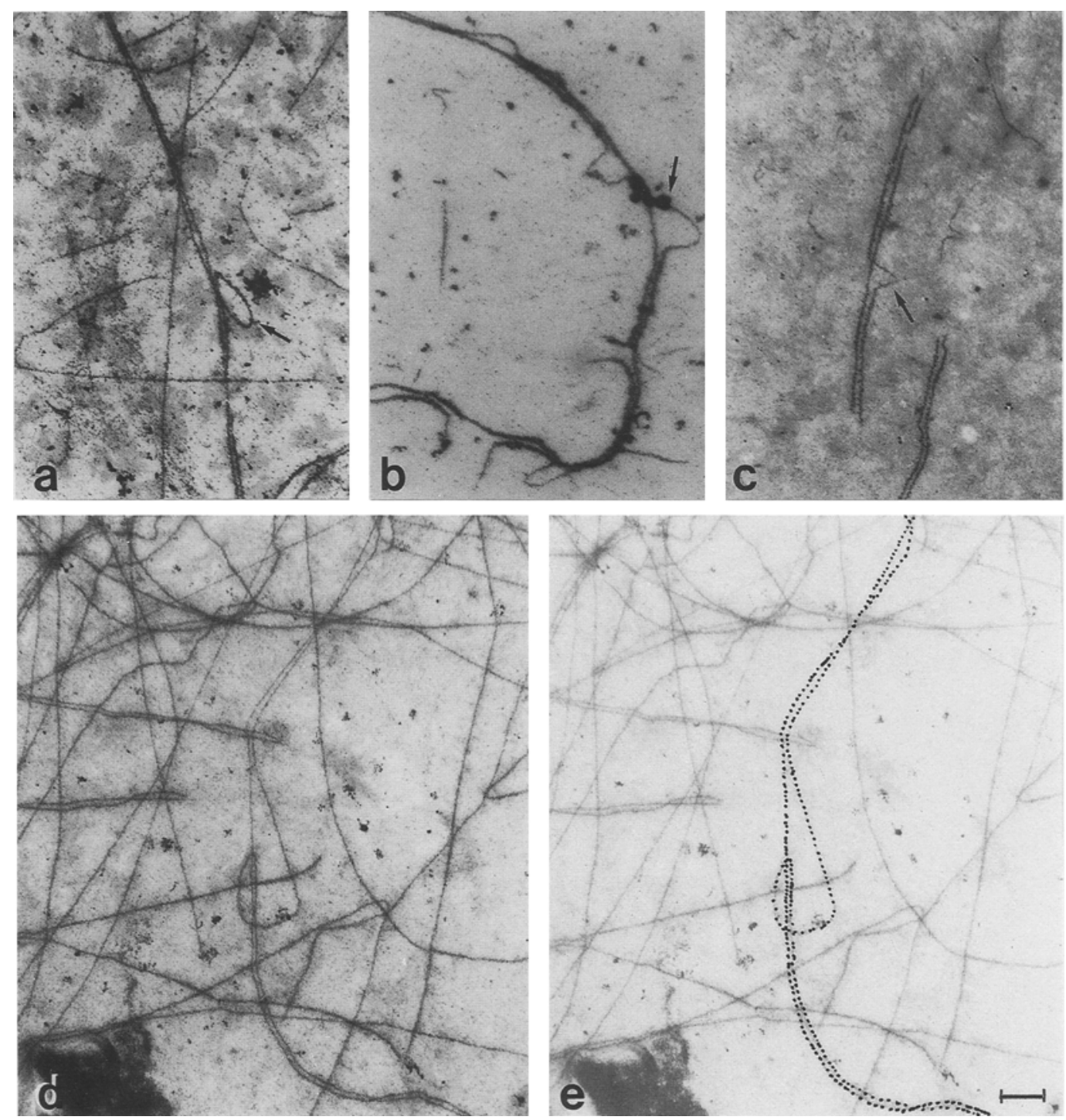

Figure 17. Micrographs showing inequality in the length of synapsed lateral components in euhaploid wheat. Figures $17 \mathrm{~d}$ and $17 \mathrm{e}$ are from a zygotene nucleus while Figures $17 \mathrm{a}-\mathrm{c}$ are from early diplotene nuclei. ( $\mathrm{Bar}=1 \mu \mathrm{m})$

the total lateral component length had been reduced from $1033 \mu \mathrm{m}$ to $425 \mu \mathrm{m}$ and the synaptonemal complex length from $428 \mu \mathrm{m}$ to $323 \mu \mathrm{m}$ (Tables VIII and IX). Thus, unpaired lateral components are primarily eliminated while the synaptonemal complex segments are more resistant and primarily degraded from the ends rather than interstitially. As a result of this degradation pattern late diplotene nuclei are characterized by short and distinct synaptonemal complex segments (Figure 21), where the lateral components in the synapsed segments have increased in width and density by the accumulation of additional electron scattering material (Figure 20). The thickening of the lateral components is initiated already at mid diplotene when the synaptonemal complex length is reduced to about half of that seen in late 

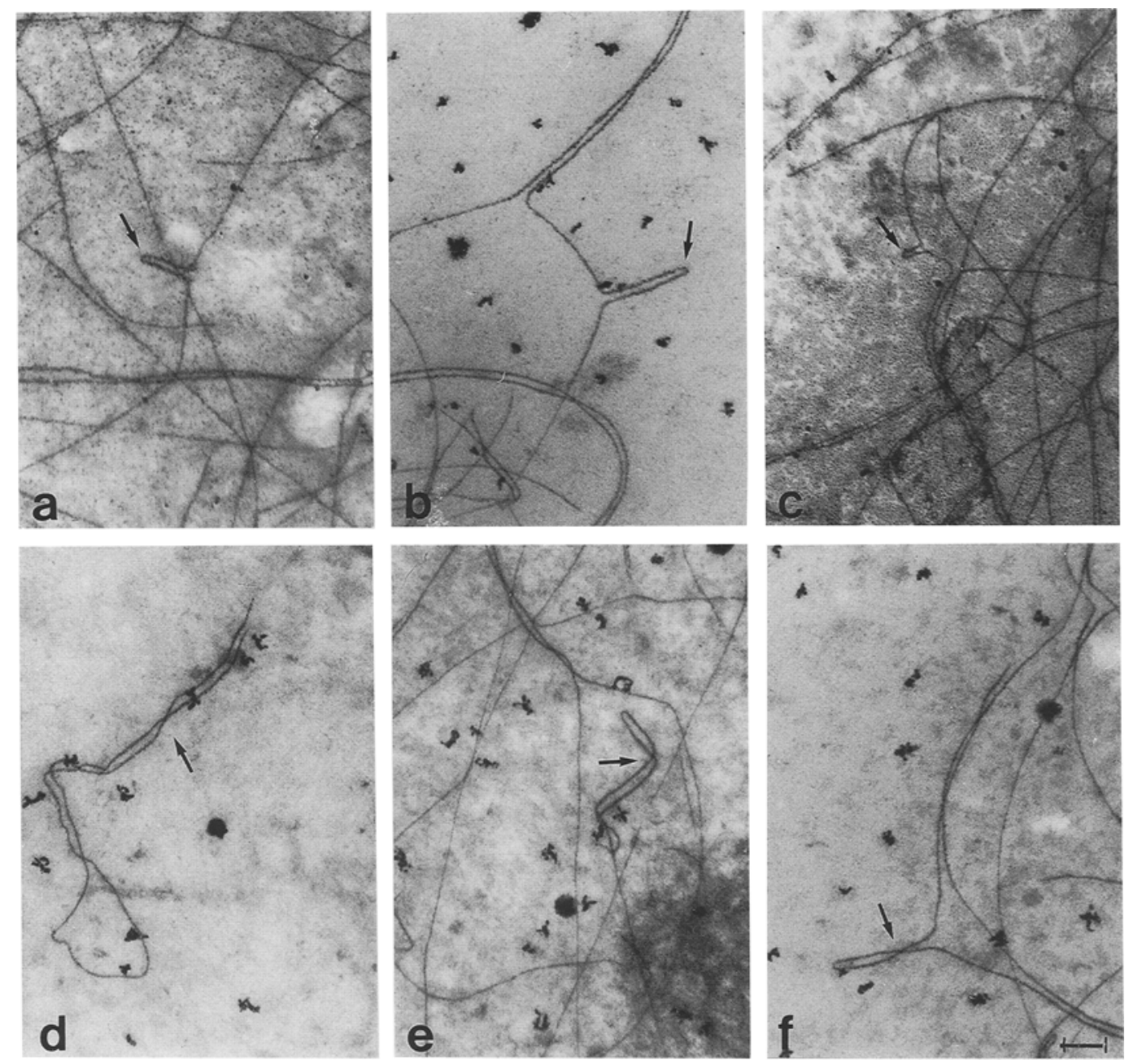

Figure 18. Micrographs showing foldback paired loops (arrows) at zygotene (Figures 18a and 18c) and at diplotene (Figures $18 \mathrm{~b}$ and $18 \mathrm{~d}-\mathrm{f})$ in euhaploid wheat. $(\mathrm{Bar}=1 \mu \mathrm{m})$

zygotene.

Several nuclei presumed to be in diakinesis were also spread and analyzed. In such nuclei the elimination of the synaptonemal complexes was complete or almost so.

\section{DISCUSSION}

\subsection{Chromosome pairing}

The present study of chromosome pairing and synaptonemal complex formation in euhaploid wheat has disclosed that synapsis is initiated by a congression of the attachment sites for the telomeres to a limited portion of the nuclear envelope, in very much the same way as in allohexaploid wheat or diploid plants and animals. Thereafter, synaptonemal complex formation is initiated, to some extent from the telomeres but primarily interstitially. Although the central region cannot be seen in the silver stained spreads, the distance between the lateral components is indicative of synaptonemal complex formation. As synapsis at the beginning of zygotene in euhexaploid wheat is highly specific 
Table VII. Total lateral component complement length, paired LC length, number of SC segments and types of associations in twenty early diplotene nuclei from euhaploid wheat of Chinese Spring. s.d., standard deviation.

\begin{tabular}{|c|c|c|c|c|c|c|c|c|c|}
\hline $\begin{array}{l}\text { Nucleus } \\
\text { number }\end{array}$ & $\begin{array}{l}\text { Total } \\
\text { LC }\end{array}$ & $\begin{array}{l}\text { Paired LC } \\
\text { length }\end{array}$ & $\begin{array}{l}\text { Number of } \\
\text { LC segments }\end{array}$ & & $\begin{array}{l}\text { Typ } \\
\text { assc }\end{array}$ & $\begin{array}{l}\text { es of } \\
\text { ociatio }\end{array}$ & $\begin{array}{l}\text { nultip } \\
\text { as }\end{array}$ & & \\
\hline ED 1 & 2621 & 1354 & 74 & & $1 \times 30$ & $1 \times 6$ & & $1 \times 3$ & $11 \times 2$ \\
\hline ED 2 & 2594 & 811 & 155 & & & & & $3 \times 3$ & $12 \times 2$ \\
\hline ED 3 & 2552 & 593 & 100 & & & & & & $19 \times 2$ \\
\hline ED 4 & 2382 & 950 & 79 & & & $1 \times 6$ & $2 \times 4$ & $2 \times 3$ & $16 \times 2$ \\
\hline ED 5 & 2136 & 1027 & 87 & & & & & $5 \times 3$ & $15 \times 2$ \\
\hline ED 6 & 1904 & 1099 & 199 & & & & $1 \times 4$ & $5 \times 3$ & $31 \times 2$ \\
\hline ED 7 & 1811 & 337 & 163 & & & & & & $14 \times 2$ \\
\hline ED 8 & 1807 & 719 & 128 & & & $1 \times 6$ & $1 \times 4$ & & $15 \times 2$ \\
\hline ED 9 & 1759 & 226 & 177 & & & & & & $12 \times 2$ \\
\hline ED 10 & 1731 & 869 & 71 & & & & & $4 \times 3$ & $17 \times 2$ \\
\hline ED 11 & 1639 & 354 & 250 & & & & & $1 \times 3$ & $19 \times 2$ \\
\hline ED 12 & 1544 & 503 & 237 & & & & $4 \times 4$ & $5 \times 3$ & $37 \times 2$ \\
\hline ED 13 & 1517 & 326 & 173 & & & & & & $21 \times 2$ \\
\hline ED 14 & 1429 & 410 & 346 & & & & & $2 \times 3$ & $26 \times 2$ \\
\hline ED 15 & 1361 & 843 & 89 & & & & & $4 \times 3$ & $17 \times 2$ \\
\hline ED 16 & 1345 & 345 & 101 & $2 \times 7$ & $1 \times 6$ & $2 \times 5$ & $1 \times 4$ & $1 \times 3$ & $12 \times 2$ \\
\hline ED 17 & 1312 & 307 & 149 & & & $1 \times 5$ & $1 \times 4$ & $5 \times 3$ & $10 \times 2$ \\
\hline ED 18 & 1282 & 755 & 89 & & & & $1 \times 4$ & $2 \times 3$ & $29 \times 2$ \\
\hline ED 19 & 1199 & 198 & 198 & & & & $1 \times 4$ & $3 \times 3$ & $13 \times 2$ \\
\hline ED 20 & 1131 & 278 & 134 & & $1 \times 6$ & $2 \times 5$ & & $5 \times 3$ & $15 \times 2$ \\
\hline Mean & 1753 & 615 & 150 & & & & & & \\
\hline \pm s.d. & 477 & 335 & 71 & & & & & & \\
\hline
\end{tabular}

Table VIII. Total lateral component (LC) complement length, paired LC length, number of SC segments and types of associations in eight mid diplotene nuclei from euhaploid wheat of Chinese Spring. s.d., standard deviation.

\begin{tabular}{|c|c|c|c|c|c|c|c|c|c|}
\hline Nucleus & & Paired & Number & Number & & \multicolumn{4}{|c|}{ Types of associations } \\
\hline MD 1 & 1280 & 933 & 139 & 71 & & $1 \times 5$ & $6 \times 4$ & $6 \times 3$ & $34 \times 2$ \\
\hline MD 2 & 1233 & 455 & 180 & 47 & $1 \times 9$ & $2 \times 6$ & & $2 \times 3$ & $25 \times 2$ \\
\hline MD 3 & 1035 & 671 & 104 & 52 & $1 \times 9$ & $1 \times 5$ & $2 \times 4$ & $2 \times 3$ & $25 \times 2$ \\
\hline MD 4 & 1034 & 240 & 309 & 89 & & & $4 \times 4$ & $9 \times 3$ & $50 \times 2$ \\
\hline MD 5 & 1031 & 411 & 477 & 19 & & & & & $17 \times 2$ \\
\hline MD 6 & 910 & 146 & 420 & 53 & & & $1 \times 4$ & $7 \times 3$ & $34 \times 2$ \\
\hline MD 7 & 883 & 192 & 396 & 73 & & & $1 \times 4$ & $11 \times 3$ & $45 \times 2$ \\
\hline MD 8 & 856 & 380 & 278 & 50 & & & & $1 \times 3$ & $40 \times 2$ \\
\hline Mean & 1033 & 428 & 288 & 57 & & & & & \\
\hline \pm s.d. & 156 & 264 & 138 & 21 & & & & & \\
\hline
\end{tabular}




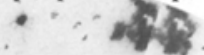


Table IX. Total lateral component (LC) complement length, paired LC length, and types of associations in nine late diplotene nuclei from euhaploid wheat of Chinese Spring. s.d., standard deviation.

\begin{tabular}{|c|c|c|c|c|c|c|c|}
\hline Nucleus & Total & Paired & Number & Number & \multicolumn{3}{|c|}{ Types of associations } \\
\hline LD 1 & 705 & 581 & 183 & 80 & & $2 \times 3$ & $70 \times 2$ \\
\hline LD 2 & 560 & 422 & 97 & 52 & & $1 \times 3$ & $39 \times 2$ \\
\hline LD 3 & 451 & 262 & 275 & 86 & $1 \times 4$ & & $83 \times 2$ \\
\hline LD 4 & 449 & 446 & 96 & 49 & & & $48 \times 2$ \\
\hline LD 5 & 436 & 348 & 139 & 51 & & & $49 \times 2$ \\
\hline LD 6 & 360 & 356 & 70 & 37 & & $1 \times 3$ & $33 \times 2$ \\
\hline LD 7 & 315 & 127 & 228 & 46 & & $1 \times 3$ & $42 \times 2$ \\
\hline LD 8 & 304 & 300 & 101 & 51 & & & $50 \times 2$ \\
\hline LD 9 & 245 & 64 & 174 & 22 & & & $22 \times 2$ \\
\hline Mean & 425 & 323 & 151 & 53 & & & \\
\hline \pm s.d. & 142 & 159 & 69 & 20 & & & \\
\hline
\end{tabular}

for homologue recognition (15), the interstitial synaptonemal complex formation may be based on a high degree of homology between intercalary segments of homoeologous chromosomes. During the remainder of zygotene, synapsis extending from the telomeres becomes more and more prominent.

Pairing partner exchanges are at early zygotene very frequent and result in formation of multiple associations which may involve virtually all lateral components of the nucleus. During the progression of synapsis pairing partner exchanges are eliminated by synaptic correction and several associations involving two or three chromosomes are formed at the expense of more complex multiple associations. Synapsis
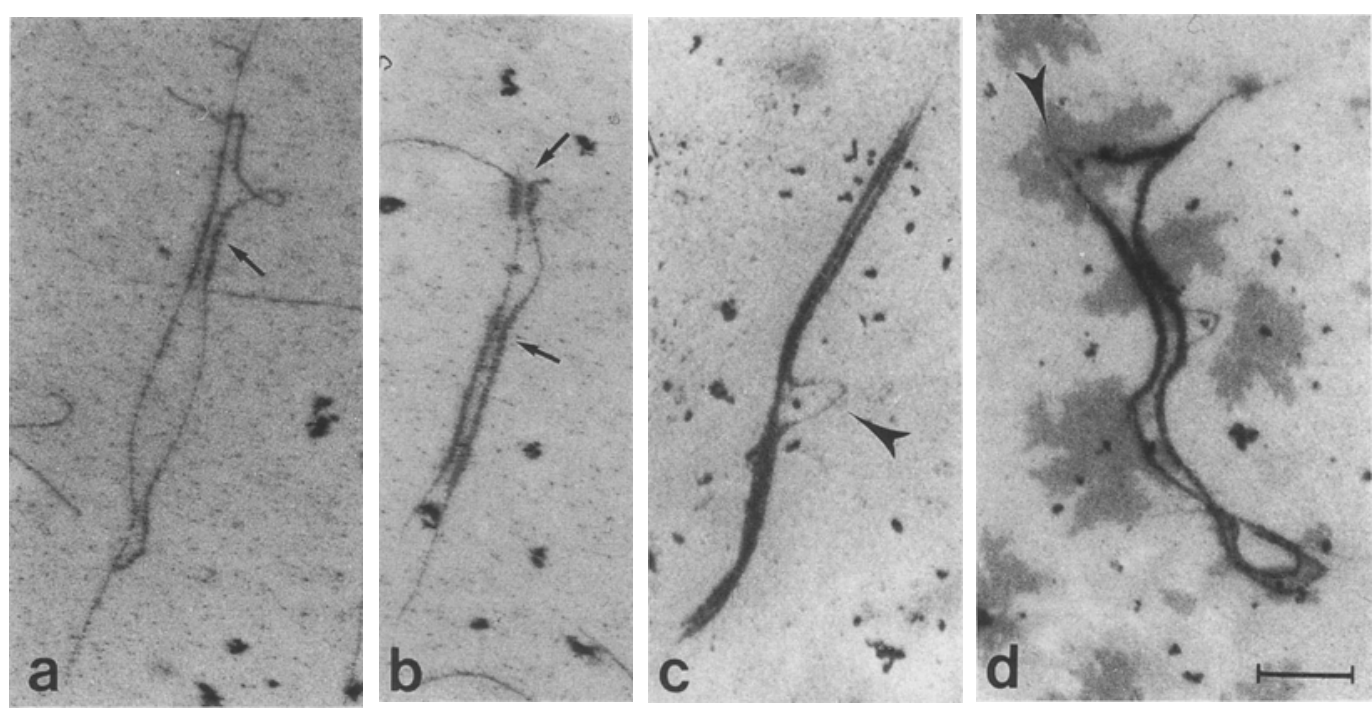

Figure 20. Micrographs illustrating the progressive thickening of lateral components in synaptonemal complexes during diplotene (arrows). Note that the unpaired segment of lateral components is not modified (arrowheads). $($ Bar $=1 \mu \mathrm{m})$ 


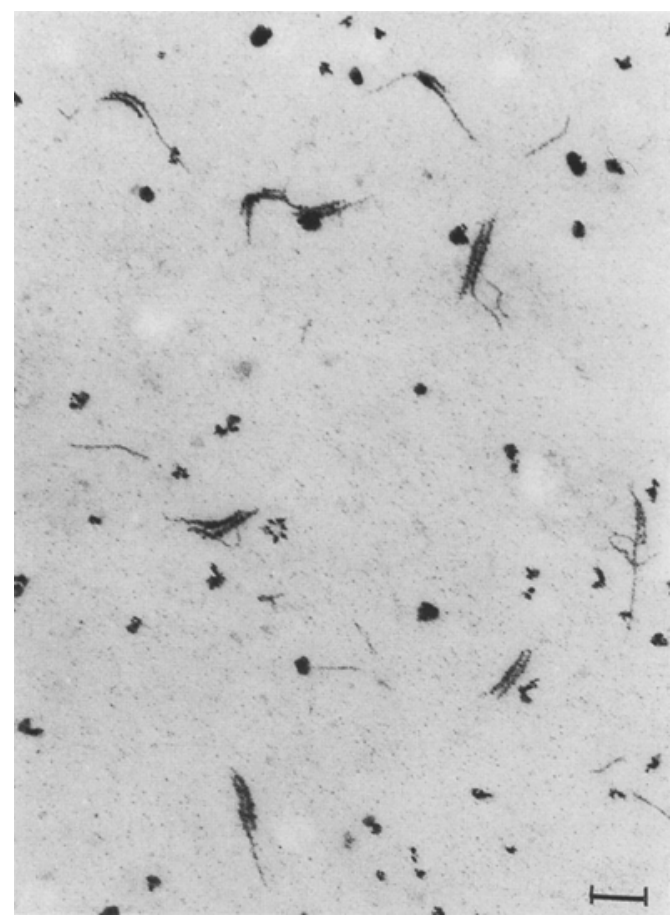

Figure 21. A micrograph of retained synaptonemal complex segments at late diplotene in euhaploid wheat. $(\mathrm{Bar}=1 \mu \mathrm{m})$

stops when on the average $35-40 \%$ of the complement is joined with a synaptonemal complex. In euhaploids of the Chinese winter wheat variety Kedong synaptonemal complex formation appears to be initiated and to proceed as in euhaploids derived from Chinese Spring but up to $90 \%$ of the complement may synapse whereas the highest degree of synapsis observed in euhaploids of Chinese Spring amounts to $41 \%$ (Table III).

Irrespective of extensive synaptonemal complex formation in the euhaploids derived from euploid or monosomic 5B Chinese Spring and euhaploids from Kedong, all three materials are virtually achiasmatic, the mean number of chiasmata per cell in the three materials being 0.14 , 0.16 and 0.23 . In contrast nullisomy for chromosome $5 \mathrm{~B}$ results in a 45 -fold increase in chiasma frequency (Table $\mathrm{I}$ ). This increase in chiasma formation in nullisomic $5 \mathrm{~B}$ haploids is correlated with a twofold increase in the number of pairing partner exchanges per lateral compo- nents and a two- to threefold increase in the number of lateral components in multiple associations involving more than three lateral components when comparing zygotene nuclei at the same stage of pairing. A discussion of these results as well as those obtained from the other investigations in this series on the effect of chromosome $5 \mathrm{~B}$ on synapsis and crossing over in wheat is given in (15).

\subsection{Elimination of the synaptonemal complex}

The present study has shown that the microsporocyte nuclei of euhaploid wheat proceed directly from zygotene to diplotene, the early diplotene nuclei possessing the same pairing characteristics, i.e. pairing partner exchanges, unpaired loops, and foldback pairing, as nuclei at late zygotene. Degradation of the unpaired lateral components and synaptonemal complexes is initiated in a few regions generating a large number of fragments. Thereafter, the unpaired lateral components are primarily eliminated, while the synaptonemal complex segments are degraded from the ends as judged by the constancy in number of synaptonemal complex segments at mid diplotene (57 segments) compared to late diplotene (53 segments). The degradation is accompanied by an increase in width and density of the lateral components of the retained synaptonemal complex segments. At diakinesis all lateral components and synaptonemal complex segments are eventually eliminated.

In diploid organisms where the degradation of the synaptonemal complex at diplotene has been monitored, strong evidence has been accumulated for the contention by WESTERGAARD and VON WETTSTEIN $(30,31)$ and SOLARI (26) that synaptonemal complex segments at diplotene are retained around crossovers (32). Thus in Sordaria (35) and Neurospora (6) nearly all retained segments possessed a recombination nodule, their number correlating with the number of chiasmata (Sordaria) or crossovers (Neurospora). Likewise, derivatives of recombination nodules, chromatin nodules, have been identified in retained synaptonemal complex segments in spermatocytes of diploid Bombyx (12). In human spermatocytes the number of distinct synaptonemal complex segments re- 
mained constant (about 70 segments) during diplotene and correlated in number and distribution with the number and distribution of crossovers inferred from an analysis of the distribution of recombination nodules at pachytene $(13,14)$. In this organism, as well as in allohexaploid wheat the elimination of the synaptonemal complexes proceeded in basically the same manner as described above for euhaploid wheat, namely an initiation of degradation at a few sites whereafter the synaptonemal complex segments primarily were degraded from the ends $(8,14)$. Thus, in allohexaploid wheat the number of synaptonemal complex segments only increased from 89 segments at early diplotene to 119 segments at mid diplotene and 136 segments at late diplotene. From this evidence it was inferred (14) that the pattern emerging after the initial breakdown of the complex reflects an inherent property of the chromosome/bivalent arm which somehow affects the structure/composition of the synaptonemal complex, where regions of high resistance to degradation also are the ones with the highest probability for crossing over at mid-late pachytene. Furthermore, it was suggested that the crossing over event in itself introduces a local structural modification of the complex making it even more resistant to degradation (14).

As euhaploid wheat is virtually achiasmatic, the retention of synaptonemal complex segments at late diplotene cannot be attributed to chiasma formation and whether synapsis between homoeologous and nonhomologous chromosome can impose structural/compositional differences on the synaptonemal complex, which can generate the observed pattern of degradation, remains to be seen. Degradation of the synaptonemal complex may alternatively in haploid wheat be entirely independent of chiasma formation, the structure and composition of the synaptonemal complex being the same irrespective of location along a pair of synapsed chromosomes. Thus, the number of retained segments at late diplotene in euhaploid wheat amounts to $39 \%$ of the number of segments found at the same stage in allohexaploid wheat which is approximately the same difference as noted in the amount of synapsis achieved in trihaploid wheat and hexaploid wheat $(35-40 \%$ versus $90 \%$ ). A possible explanation which can account for the retention of synaptonemal complex segments at late diplotene could, however, be that resistance to degradation is induced by binding of recombination nodules and/or initiation of crossing over. As discussed in (15), the prevention of crossing over between homoeologues of wheat in the presence of the $\mathrm{Ph}$ gene or chromosome $5 \mathrm{~B}$ may be attributed to a stringent control of heteroduplex formation between synapsed chromosome segments. Binding of recombination nodules or initiation of heteroduplex formation may, however, not be affected.

\section{ACKNOWLEDGEMENTS}

I am indebted to Dr. Preben B. Holm, Professor Diter von Wettstein, Dr. Søren W. RasMUSSEN and Cand. scient. BENTE WISCHMANN for discussion and review of the manuscript. The expert technical assistance of BIBI STAMPE ANDERSEn, JEAN SAGE, Nina Rasmussen and ANNSOFI STEINHOLTZ is gratefully acknowledged. The work was supported by grant BI6-E-168DK from the Commission of the European Communities.

\section{REFERENCES}

1. Abirached-Darmency, M., Y. Cauderon \& D. ZJCKLER: Meiotic chromosome pairing in three $\mathrm{Fl}$ (Triticum-Secale) hybrids: A comparative approach in light and electron microscopy. Biol. Cell 51, 365-372 (1984)

2. Brown, M.S.: The implications of pachytene metaphase pairing for species differentiation. Proc. X. Int. Cong. Genet. 2, 36 (1958)

3.Chuang, C.C. \& J.W. OuYanG: A set of potato media for wheat anther culture. In: Proc. Symp. Plant Tissue culture. Science Press, Beijing, China, pp. 51-56 (1978)

4. Chuang, C.C. \& X. JIA: Studies on the differentiation of pollen calli of wheat. In: Ann. Rep. Inst. Genet. Academia Sinica, Beijing China, pp. 73-74 (1980)

5. Gillies, C.B.: The nature and extent of synaptonemal complex formation in haploid barley. Chromosoma 48, $441-453$ (1974)

6. GILLIES, C.B.: The relationship between synaptonemal complexes, recombination nodules and crossing over in Ceurospóra crassa bivalents and 
translocation quadrivalents. Genetics 91,1-17 (1979)

7. Новоцтн, P.: Chromosome pairing in allohexaploid wheat var. Chinese Spring. Transformation of multivalents into bivalents, a mechanism for exclusively bivalent formation. Carlsberg Res. Commun. 46, 129-173 (1981)

8. Holm, P.B.: Chromosome pairing and chiasma formation in allohexaploid wheat, Triticum aestivum analyzed by spreading of meiotic nuclei. Carlsberg Res. Commun. 51, 239-294 (1986)

9. HOLM, P.B.: Chromosome pairing and synaptonemal complex formation in hexaploid wheat, monosomic for chromosome 5B. Carlsberg Res. Commun. 53, 57-89 (1988)

10. HoLm, P.B.: Chromosome pairing and synaptonemal complex formation in hexaploid wheat, nullisomic for chromosome 5B. Carlsberg Res. Commun. 53, 91-110 (1988)

11. HoLm, P.B.: Chromosome pairing and synaptonemal complex formation in hexaploid wheat, monoisosomic and diisosomic for the long arm of chromosome 5B. Carlsberg Res. Commun. 53, 111-133 (1988)

12. Holm, P.B. \& S.W. RASMUSSEN: Chromosome pairing, recombination nodules and chiasma formation in diploid Bombyx males. Carlsberg Res. Commun. 45, 483-548 (1980)

13. Holm,P.B. \& S.W. RasmuSSEN: Human meiosis VI. Crossing over in human spermatocytes. Carlsberg Res. Commun. 48, 385-413 (1983)

14. HoLm, P.B. \& S.W. RaSMUSSEN: Human meiosis VII. Chiasma formation in human spermatocytes. Carlsberg Res. Commun. 48, 415-456 (1983)

15. HoLm, P.B.\& X. W ANG: The effect of chromosome $5 \mathrm{~B}$ on synapsis and chiasma formation in wheat, Triticum aestivum cv. Chinese Spring. Carlsberg Res. Commun. 53, 191-208 (1988)

16. Jenkins, G.: Chromosome pairing in Triticum aestivum cv. Chinese Spring. Carlsberg Res. Commun. 48, 255-283 (1983)

17. MCClintock, B.: The association of non-homologous parts of chromosomes in the midprophase of meiosis of Zea mays. Zeits. Zellforsch. \& Mikro. Anat. 19, 191-237 (1933)

18. Menzel, M.Y. \& J.M. PRice: Fine structure of synapsed chromosomes in F1 Lycopersicon esculentum -Solanum lycopersicoides and its parents. Amer. J. Bot. 53, 1079-1086 (1966)

19. OKamoto, M. \& E.R. Sears: Chromosomes involved in translocations obtained from haploids of common wheat. Can. J. Genet. Cytol. 4, 24-30 (1962)

20. RIEGER, R.: Inhomologen Paarung und Meioseablauf bei haploiden Formen von Antir- rhinum majus L. Chromosoma 9, 1-38 (1957)

21. RILEY, R.: The diploidisation of polyploid wheat. Heredity 15, 407-429 (1960)

22. Riley, R. \& C. Kempanna: The homoeologous nature of the non-homologous meiotic pairing in Triticum aestivum deficient for chromosome $\mathrm{V}$ (5B). Heredity 18, 287-306 (1963)

23. SEARS, E.R: The aneuploids of common wheat. Mo. Agric. Exp. Stu. Res. Bull. 572, 58 pp. (1954)

24. SEN, S.K: Synaptonemal complexes in haploid Petunia and Antirrhinum sp.. Naturwissenschaften 57,550 (1970)

25. Shimada, T. \& T. Makino: In vitro culture of wheat. III. Anther culture of the A genome aneuploids in common wheat. Theor. Appl. Genet. 46, 407-410 (1975)

26. SOLARI, A.J.: The behaviour of chromosomal axes during diplotene in mouse spermatocytes. Chromosoma 31, 217-230 (1970)

27. TING, Y.C.: Synaptonemal complex of haploid maize. Cytologia 38, 497-500 (1973)

28. WANG, $X$ \& P.B. HoLM: Chromosome pairing and synaptonemal complex formation in wheat-rye hybrids. Carlsberg Res. Commun. 53, 167-190 (1988)

29. WANG, X.\& H. Hu: The chromosome constitution of plants derived from pollen of hexaploid triticale $x$ common wheat $F_{1}$ hybrids. Theor. Appl. Genet. 70, 92-96 (1985)

30. WestergaARD, M. \& D. von WetTStein: The meiotic cycle in an ascomycete. In: Effects of radiation on meiotic systems. Internat. Atom. Energy Agency. Panel Proc. Sci. Pub. 173, 113-121 (1968)

31. Westergaard, M. \& D. von Wettstein: Studies on the mechanism of crossing-over IV. The molecular organization of the synaptonemal complex in Neottiella (Cooke) Saccardo (Ascomycetes). Compt. Rend. Trav. Lab. Carlsberg 37, 239-268 (1970)

32. WetTSTEIN, D. von, S.W. RASMUSSEN \& P.B. Holm: The synaptonemal complex in genetic segregation. Ann. Rev. Genet. 18, 331-431 (1984)

33. Wischmann, B.: Chromosome pairing and chiasma formation in wheat plants triisosomic for the long arm of chromosome 5B. Carlsberg Res. Commun. 51, 1-25 (1986)

34. ZHANG, Y. \& D. LI: Anther culture of monosomics in Triticum aestivum. Hereditas (Beijing) 6, 7-10 (1984)

35. ZICKLER, D.: Development of the synaptonemal complex and the "recombination nodules" during meiotic prophase in the seven bivalents of the fungus Sordaria macrospora Auersw. Chromosoma 61, 289-316 (1977)

Accepted by E. LUND 